\title{
Crisis financiera mundial: su impacto social y político en Centroamérica
}

Luis Armando GonZÁLEZ*

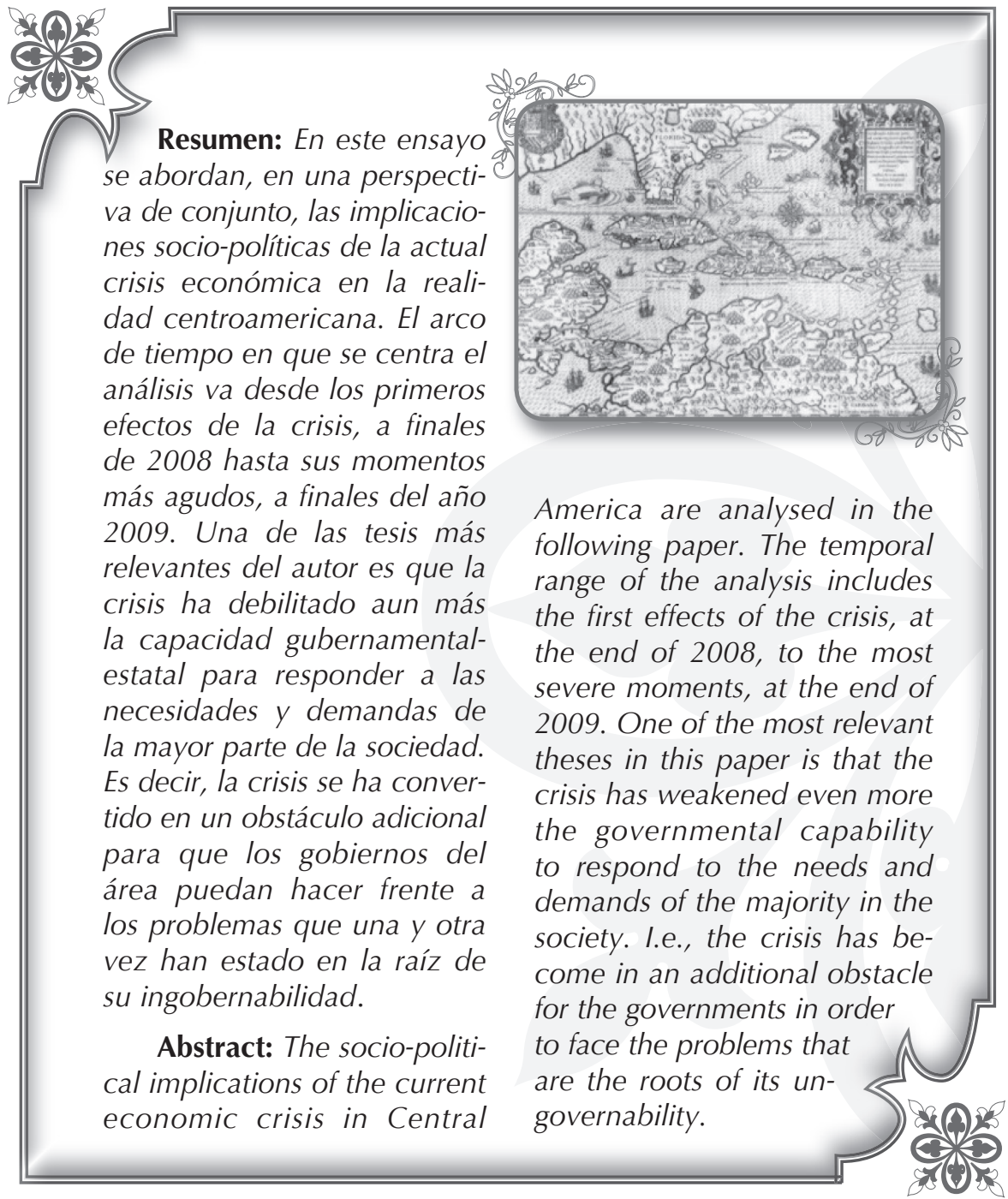




\section{Introducción}

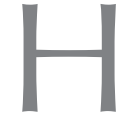

ay que destacar que el impacto de la crisis financiera mundial en el ámbito estrictamente económico es lo que más se discute en la actualidad. Si bien el examen de las implicaciones estrictamente económicas es un primer paso para dimensionar su impacto social, es pertinente complementarlo con la sostenibilidad financiera de los estados, fijando la atención en la situación de los recursos destinados a programas sociales cuya finalidad es disminuir los niveles de exclusión, pobreza y marginalidad de carácter secular. Las medidas impulsadas para enfrentar los efectos coyunturales de la crisis económica deberían pensarse no sólo en función de su sostenibilidad financiera en el tiempo o de su eficacia en la contención de los efectos negativos de la misma, sino también en el efecto regresivo que su financiamiento podría tener en la distribución de la riqueza de los países, profundizando de esta manera la disparidad de ingresos.

Esos programas, impulsados con anterioridad a la crisis, nacieron de la convicción, en distintos sectores políticos y sociales, de que la pobreza, la exclusión y la marginalidad no sólo eran factores que favorecían comportamientos sociales anómicos, sino que contribuían a la proliferación de prácticas violentas de distinta naturaleza. Anomia, frustración colectiva y violencia son tres de los problemas sociales más graves que los países centroamericanos, con menor o mayor intensidad (y con la excepción de Costa Rica), se han propuesto combatir, prestando atención a los condicionantes económico-sociales (pobreza, marginalidad, exclusión) que, se entiende, estaban en su raíz.

Se diseñó un conjunto de políticas sociales que harían frente a esos condicionantes. Esas políticas estaban en marcha cuando estalló la crisis. Se diseñaron otras políticas —como por ejemplo, el "plan anticrisis" en El Salvador-, esta vez para paliar el impacto de la crisis sobre los sectores sociales vulnerables (a los que se estaba atendiendo o se iba a atender con anterioridad a la crisis). ¿Han sido sostenibles financieramente unas $y$ otras en todos los países del área que las impulsaron? Hay que ver las experiencias concretas. De todos modos, una respuesta negativa no conduciría más que a reconocer no sólo la prevalencia de graves problemas sociales, sino también la existencia de un cúmulo de demandas sociales insatisfechas que ahora como antes - con el agravante del impacto de la crisis- se buscaría canalizar fuera o al margen de unos aparatos institucionales-estatales que no han sido capaces de procesarlas y darles una respuesta oportuna. Lo anterior conecta con el impacto de la crisis en las po- 
líticas sociales de los estados de la región. Hay que decir que, en Centroamérica, con excepción de Costa Rica, la década de los años noventa, además de caracterizarse por graves problemas de pobreza, exclusión, inseguridad y violencia, se cerró con una grave amenaza de ingobernabilidad, erosión de la institucionalidad, falta de credibilidad y desconfianza ciudadana en la capacidad del sistema político para responder a las demandas sociales más urgentes.

El nuevo siglo vio nacer un conjunto de esfuerzos gubernamentales más orientados a enfrentar los problemas de inseguridad y violencia que a disminuir la exclusión y la pobreza. No es que estos dos temas no aparecieran en las agendas de gobierno y que no se destinara algún tipo de recursos a paliarlos. Sin embargo, no fue fácil establecer una conexión entre exclusión y pobreza, por una parte; y la criminalidad, la inseguridad y la violencia, por la otra. Ni mucho menos tomar en serio la conexión entre las primeras y la erosión institucional, las amenazas a la ingobernabilidad $y$, en definitiva, la incertidumbre en los procesos de democratización. Costaba entender que la exclusión y la pobreza eran y son caldo de cultivo no sólo de desarraigo social, sino de desconfianza en los cauces institucionales y políticos establecidos.

En los momentos anteriores a la crisis financiera, importantes virajes políticos se suscitaron en Nicaragua, Honduras y Guatemala, mis- mos que expresaban la insatisfacción ciudadana con un tipo de gestión económica y política que le dio la espalda a sus necesidades. En los nuevos gobiernos que se instauraron en esos países, ha sido claro el compromiso por impulsar políticas sociales que contribuyan a atacar de manera sensible el problema de la exclusión y la pobreza. En El Salvador, con menos determinación, el gobierno de Antonio Saca, hizo una apuesta por programas sociales que también apuntaban a enfrentar la pobreza y la exclusión. En Costa Rica, los esfuerzos del gobierno de Óscar Arias se han centrado no tanto en impulsar políticas sociales inéditas, sino en mantener vigentes y dar sostenibilidad a las que caracterizan al modelo costarricense desde los años 40 del siglo XX. Esta era la dinámica centroamericana cuando los efectos de la crisis se comienzan a sentir con fuerza.

¿Cómo ha impactado la crisis los proyectos sociales impulsados por los gobiernos de Guatemala, Honduras y Nicaragua? ¿Cómo han impactado los programas sociales diseñados en El Salvador? ¿Cuál es la situación que hereda, en este último país, la nueva administración de izquierda en materia de sostenibilidad de los programas sociales heredados y los nuevos que se iban a impulsar? ¿Cómo ha impactado la crisis en el modelo de bienestar costarricense? Preguntas semejantes hay que hacerse respecto de los planes seguridad pública y combate de la violencia, sobre todo en los 
países afectados por la criminalidad y la violencia. Y, posteriormente, está la ponderación del impacto político que ello pueda tener tanto en materia de gobernabilidad como de institucionalidad. Prácticamente, con los matices propios de Costa Rica y Panamá —país este último en el cual el impacto de la crisis coincidió con un relevo conservador en el gobierno-, el impacto ha tenido que ser administrado por gobiernos de izquierda o inclinados hacia esta tendencia política. El triunfo de estos gobiernos es una respuesta al malestar ante gestiones de derecha (o inclinadas hacia ella) que apostaron excesivamente por las fuerzas del mercado como motor de desarrollo socio-económico.

El compromiso de las nuevas administraciones es -al menos retóricamente- enfrentar drásticamente la pobreza y la exclusión, como punto de partida para atacar la violencia, la inseguridad y el crimen, pero también para fortalecer las instituciones, hacer gobernables a las sociedades y avanzar hacia una democracia firme. Dicho de manera gráfica, la idea es recorrer el camino inverso que antes se quiso seguir, es decir, el camino que fue de lo político (arreglos para finalizar los conflictos) a lo económico (ajuste, privatización y apertura comercial) y de aquí a lo social (bienestar conseguido como resultado del "rebalse"). El problema, sin embargo, es que el compromiso fundamental de los nuevos gobiernos centroamericanos ha sido puesto en cuestión por el impacto de la crisis. Lo cual sugiere que dinámicas criminales y de violencia, así como dinámicas de desconfianza política-institucional, seguirán vigentes, mientras los efectos de la crisis no se reviertan y los gobiernos no pueden echar a andar las políticas sociales prometidas.

En resumen, antes de la llegada de gobiernos inclinados hacia la izquierda (con las variantes respectivas para cada país) la visión que predominaba era la siguiente: lo importante es el crecimiento económico del cual se derivará el bienestar social y la democracia. Los años pasaron, hubo crecimiento pero no hubo bienestar social ni tampoco avances sustanciales en la democratización, especialmente en el fortalecimiento de las instituciones que la deben sostener. Al contrario, la pobreza, la violencia y la erosión institucional se convirtieron en la contracara del crecimiento económico. La postura asumida por los nuevos gobiernos se caracterizó por intentar potenciar el bienestar social como supuesto para disminución de los niveles de violencia y la profundización democrática — tal como la experiencia de Costa Rica lo había demostrado con mucha anticipación-. Incluso en El Salvador, pese a que el discurso de la rentabilidad y el mercado era predominante en la administración Saca, también se estaban abriendo las puertas a un discurso que apuntaba a privilegiar los programas de bienestar social. El triunfo electoral de Mauricio Funes 
y el FMLN puso a El Salvador en sintonía con lo que estaba sucediendo en Guatemala, Nicaragua y Honduras. Pero se desató la crisis, que amenaza con socavar los esfuerzos por hacer del bienestar social de los pueblos centroamericanos la base de una convivencia pacífica y democrática.

Circunscribiendo esta discusión al impacto económico y social de la crisis, así como a los implicaciones de la misma para la gobernabilidad de las países centroamericanos, no se debe menospreciar, por un lado, su impacto económico específico en la dinámica productiva; $y$, por otro, su impacto social, tanto por la vía de su incidencia en la dinámica de la economía familiar como por sus efectos en los planes sociales de los gobiernos. Con lo anterior como trasfondo, se tiene que proceder a un examen de la dinámica socio-política de la región —que es precisamente lo que se hace en este ensayo-, con el propósito de leer sus signos de agudización — de los cuales el golpe de Estado en Honduras es el más significativo- no como "causado" por la crisis económica, sino como algo que con la crisis se hizo más difícil de resolver. Dicho lo anterior, en este ensayo se hace una aproximación al impacto social y político de la crisis. Se parte de una visión general de las implicaciones de la misma, para luego hacer un examen -más en detalle- de sus implicaciones sociales y políticas. Se concluye con un conjunto de reflexiones acerca de los desafíos que plantea a la gobernabilidad democrática centroamericana el impacto de la crisis y su entrelazamiento con los procesos que, con anterioridad o independencia de ella, marcan actualmente a la región.

\section{Visión de conjunto de la región}

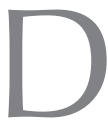

esde finales de 2008, la preocupación por el impacto de la crisis económica mundial comenzó a cobrar fuerza en Centroamérica. No fue, sin embargo, hasta bien entrado el año 2009 que, al calor de unos efectos que ya eran sensibles en el ámbito socio-económico, esa preocupación se hizo evidente tanto a nivel de agentes políticos y empresariales como a nivel de la sociedad en general. Sin entender bien los factores que la desencadenaron, vislumbrar su posible duración ni entender bien el alcance de sus efectos, no sólo económicos y sociales, sino también políticos, los gobiernos del área intentaron - unos con mayor celeridad que otros- responder a su impacto económico y social con medidas de emergencia, cuya efectividad para hacer frente al desafío que se tenía (y se tiene) por delante todavía está por evaluarse. 
De todos modos, el menor o mayor éxito de los gobiernos centroamericanos para atender la crisis depende no sólo de su habilidad y creatividad para diseñar y ejecutar las medidas más eficaces, sino del contexto económico, social y político previo a la crisis y que condiciona fuertemente su capacidad de gestión de la misma. $Y$ es que el impacto de la crisis no se da en el vacío, sino que se traslapa con unos dinamismos previos - económicos, sociales y políticos-, cuyas aristas más graves ha contribuido a agudizar, principalmente en los países del Ilamado Triángulo Norte (EI Salvador, Honduras y Guatemala).

Muchos de esos dinamismos previos (que constituyen el contexto en el que impacta la crisis) revisten un carácter estructural (como la pobreza, el deterioro de los sistemas agrícolas, la inseguridad alimentaria o los bajos salarios), mientras que otros, sin llegar a serlo, han adquirido tal permanencia (como la violencia asociada a las pandillas o el crimen organizado regionalizado) que pueden ser definidos como casi estructurales.

Asimismo, con anterioridad a la crisis, la región experimentaba importantes procesos de organización y movilización sociales, en cierto modo, inéditas. $Y$ es que -lejos de circunscribirse el movimiento social tradicional (como los sindicatos o los gremios, y sus respectivas demandas) — incluía a sectores tan dispares como los pobladores campesinos, vendedores ambulantes, pequeños comerciantes del sector informal urbano y transportistas, cuyas demandas, igualmente dispares, iban desde la resistencia frente a los proyectos mineros y de construcción de presas hidroeléctricas hasta los reclamos por los efectos de la contaminación, ampliación de los niveles de participación y malestar creciente ante la forma cómo habían sido gestionadas las sociedades en el marco del proyecto neoliberal que se implementó en la región una vez que el conflicto centroamericano fue desactivado en la primera mitad de los años noventa del siglo XX.

Junto a lo anterior $-y$ en parte debido a ello - la mayor parte de los países del área comenzó a experimentar, siempre con anterioridad a la crisis, importantes cambios políticos caracterizados por el creciente predominio de tendencias políticas de izquierda y de centro izquierda, que supieron aprovechar el malestar de amplios sectores sociales ante gobiernos con filiación de derecha que no habían sabido hacer frente a problemas económicos y sociales que afectaban directamente a la mayor parte de la población, especialmente a sus grupos más vulnerables.

No hubo una sincronización exacta en estos procesos de cambio político - en parte por la diferencia en los calendarios electorales; en parte, por la cultura política y la trayectoria particular de cada país-, pero lo que cabe destacar es una especie de ola que terminó por mo- 
ver políticamente a amplios sectores sociales desde una preferencia por las opciones de derecha hacia una preferencia por opciones de izquierda y centro izquierda.

Nicaragua es el país en el cual el cambio aludido es más evidente; se ha tratado de una especie de retorno a un sandinismo redefinido que, con Daniel Ortega electo como presidente en noviembre de 2006, se tradujo en un vínculo firme con la República Bolivariana de Venezuela. Con matices y con un tono distinto, los gobiernos de Guatemala (encabezado por Álvaro Colom, electo presidente de su país en noviembre de 2007) y de Honduras (encabezado por Manuel Zelaya, quien asumió la presidencia de su país el 27 de enero de 2006) se pusieron en sintonía con las ansias de cambio expresadas por amplios sectores de sus respectivas naciones.

A esta dinámica regional se sumó El Salvador, cuando el 15 de marzo de 2009 el entonces candidato presidencial por el FMLN, Mauricio Funes, derrotó al Rodrigo Ávila, de ARENA, partido de derecha que había controlado el Ejecutivo desde 1989. Hay que añadir a este cuadro general, por un lado, a Costa Rica, que bajo un segundo mandato de Óscar Arias (electo de nuevo presidente en 2006'1), ha podido mantenerse, sin mayores sobresaltos, en el esquema político socialdemócrata propio de su trayectoria histórica. Y por otro lado está Panamá, que tuvo un cambio de gobierno -en julio 2009, el empresario Ricardo Martinelli reemplazó en el Ejecutivo a Martín Torrijos, luego de derrotar (en mayo) a la candidata del Partido Revolucionario Democrático (PRD), Balbina Herrera-, sin que ello supusiera un cambio drástico - por los menos en los primeros meses del nuevo gobierno- en la estructura del Estado panameño ni en los modos cómo se orientan las políticas públicas en ese país.

Del conjunto de los países mencionados, tres de ellos no se han visto sacudidos por crisis políticas abiertas: Nicaragua, Costa Rica y Panamá. Del resto, en Guatemala el presidente Colom enfrentó una fuerte ofensiva por parte de sectores de derecha de su país y en Honduras el presidente Zelaya fue depuesto, el 28 de junio de 2009, mediante un golpe de Estado. $\mathrm{Y}$ en El Salvador el gobierno de Funes vio cerrar sus cien días no sólo con la amenaza, lanzada por el ex presidente Alfredo Cristiani, de que si se removía del aparato estatal a miembros de ARENA en el país iba "a arder Troya", sino con la afirmación por parte de un ex ministro de defensa de que el golpe de Estado en Honduras no era ni el primer ni el último del que se tendría noticia en América Latina.

La crisis económica, en este sentido, encuentra a la región centroamericana inmersa en un marco de problemas, algunos de los cuales atañen más al conjunto de la región (como las oportunidades y 
los riesgos que entrañan los TLC); otros, a bloques de países (como las pandillas, el crimen organizado o las migraciones intra-regionales) y otros, por último, que tienen que ver con los procesos políticos, económicos y sociales de cada país en particular. Se trata, aquí, obviamente de una distinción analítica, puesto que - como pone de manifiesto la actual crisis en Honduras - los problemas gruesos de cada país tienen (o están llamados a tener) una repercusión centroamericana y su solución también exige un esfuerzo conjunto de las naciones del área.

El impacto específico de la crisis debe deslindarse de situaciones problemáticas (económicas, sociales y políticas) que son previas a la misma, pero que no le son ajenas (directa o indirectamente). Así, es indudable que la crisis ha tenido un fuerte impacto en los ámbitos económico y social, pues no sólo ha afectado al sistema productivo o la capacidad de consumo de la sociedad, sino también las finanzas públicas. Por esta última vía, ha socavado la capacidad de los nuevos gobiernos para atender la gran diversidad de necesidades $y$ demandas sociales, cuya insatisfacción generó el malestar que fue el que llevó al descrédito (y a la derrota electoral) a los gobiernos con filiación ideológica de derecha (Nicaragua, Guatemala y El Salvador), o que un presidente salido de las filas conservadoras decidiera asumir la causa del socialismo para el siglo XXI (Honduras).
Con la excepción de Costa Rica y Panamá, los demás países centroamericanos estaban atravesando, antes del estallido de la crisis, por procesos de organización y movilización sociales que expresaban una profunda insatisfacción con la forma de organización económica (que para esos sectores significa miseria y abandono), pero también con la prevalencia de mecanismos que excluyen a la sociedad de la toma de decisiones en los asuntos públicos. La amenaza de ingobernabilidad estaba al acecho de estas sociedades prácticamente desde finales de los años noventa; la primera mitad del 2000 no fue ajena a desbordes sociales que, intermitentemente, crearon inestabilidad y anunciaron malos tiempos para la gobernabilidad democrática en la región.

En Honduras, El Salvador y Guatemala —aunque también en Nicaragua- el giro político hacia la izquierda constituye una especie de oportunidad de "desactivación" de la bomba de tiempo de la ingobernabilidad que se forjó en las dos décadas previas, en el marco de gestiones estatales de un fuerte signo neoliberal. Desactivar la bomba de tiempo de la ingobernabilidad - con todo lo que ello supone de caos, anomia, violencia y caos- no va a ser fácil, porque se va a tener que ir en contra de resistencias estructurales que sólo pueden ser vencidas en el largo plazo. La piedra de toque será el diseño y ejecución de políticas públicas orientadas a hacer de lo social la prioridad de 
la gestión gubernamental. Políticas públicas que deben estar sostenidas por un aparato productivo eficiente y competitivo, además de por un sistema fiscal justo y solvente.

Este es el propósito —nada fácil de realizar, e incluso utópico en muchos sentidos- con el que se han declarado comprometidos prácticamente todos los gobernantes democráticamente electos de la región; sin embargo, vino la crisis y su impacto no sólo sobre el aparato productivo y las finanzas públicas, sino sobre los ingresos familiares en concepto de remesas. O sea, la crisis, además de su impacto económico directo, tiene un impacto no menos directo en la sociedad, a la cual sumerge más en la precariedad.

Como resultado de ello, la crisis tiene también un impacto — quizás más indirecto que directo- sobre la política, en el sentido de que debilita aun más la capacidad gubernamental-estatal para responder a las necesidades y demandas de la mayor parte de la sociedad. Es decir, la crisis se convierte en obstáculo adicional para que los gobiernos del área - especialmente los del Triángulo Norte y Nicaragua- puedan hacer frente a las precariedades, miserias y exclusiones endémicas de sus respectivas naciones, precariedades, miserias y exclusiones que una y otra vez han estado en la raíz de su inestabilidad socio-política, esto es, de su ingobernabilidad.

La gran pregunta es si los gobiernos centroamericanos presionados por el impacto de la crisis - tienen la capacidad y los recursos para desactivar esa bomba de tiempo de la ingobernabilidad. Obviamente, lo primero es atender, con la mayor solvencia posible, el impacto económico y social de la crisis, pero en seguida deben prestar la debida atención a problemas de carácter más estructural, que son los que en última instancia han alimentado la secular propensión a la ingobernabilidad que ha caracterizado, con excepción de Costa Rica, históricamente a las nacionales del área.

\section{Implicaciones socio-políticas de la crisis}

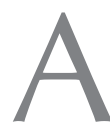
nte todo, se tiene que señalar que una cosa son los efectos sociales y económicos de la crisis y otra sus implicaciones sociales y políticas, entendiendo por esto último los dinamismos socio-políticos generados en respuesta (o como reacción) a ella. Se trata de procesos de distinto carácter, pues el primero apunta al impacto real de la crisis, en tanto que el segundo al modo cómo se responde en ella en los planos social y político. No se trata de una conexión mecánica ni automática entre ambos procesos, pues para que suceda lo segundo se requiere no sólo de una convicción subjetiva, socialmente compartida, 
de que los actores gubernamentales tienen algún tipo de responsabilidad en su gestación o en su impacto social -y que, en consecuencia, tienen que hacer algo para aliviar sus efectos-, sino de las mediaciones organizativas que permitan canalizar el malestar y las demandas de los sectores sociales insatisfechos. O sea, la conexión entre el impacto de la crisis y la respuesta ante ella por parte de los distintos actores socio-políticos está mediada por convicciones subjetivas —así como por modos y estilos de hacer las cosas - que tienen que ver con dinámicas culturales que son las que nutren los imaginarios y las prácticas de aquéllos. Son esas convicciones, así como los modos y estilos de hacer las cosas —arraigados en matrices culturales determinadas y en las prácticas correspondienteslas que han marcado las respuestas de las sociedades centroamericanas ante el impacto de la crisis.

Asimismo, además de lo anterior, para que una crisis económica genere reacciones sociales y políticas significativas —esto es, que desafíen la gobernabilidad- cuenta el contexto socio-político en el que la misma impacta: puede haber dinamismos socio-económicos y políticos que diluyan el impacto de la crisis o puede haberlos que se le subordinen, convirtiéndola en catalizadora de las contracciones existentes. Precisamente, ese fue el carácter que revistieron las crisis que se suscitaron en América Latina, en los años noventa y prin- cipios del 2000, y que han Ilevado a plantear la tesis del "rupturismo social" como "una expresión de movilización de protesta extendida y violenta que apunta a cuestionar la institucionalidad vigente en un país determinado $y$, en algunos casos, de manera muy especial y fundamental, su modelo económiCO, aun cuando no se encuentre consolidado o esté en los inicios de su implantación"2.

Aunque reconocemos que sobre el tema de la gobernabilidad existen diversas posturas, la que asumimos aquí es la versión según la cual la ingobernabilidad está asociada a tres factores: (a) erosión de la autoridad; (b) sobrecarga del gobierno; y (c) intensificación de la competencia política. Estos fueron los aspectos que destacó la Comsión Trilateral, en 1975, en su Informe sobre la Gobernabilidad. Diego Achard y Manuel Flores resumen así las tesis de este informe: "sea porque no se atiende al cúmulo de demandas o porque se atienden artificialmente en un principio - hasta que lo permiten la falta de competitividad, el endeudamiento y la inflación- lo cierto es que la limitación estatal para resolver el problema determina una pérdida de confianza pública en la capacidad del Estado; una eventual y consecuente crisis de legitimidad del mismo, que en situaciones extremas se sostenía que podía derivar en una crisis de democracia (...) y, desde ya, en una crisis política manifestada en el desencanto, la apatía y la malaise -el 
Estado de malestar - ciudadanas respecto de los actores políticos y al propio Estado" ${ }^{3}$.

En el presente ensayo, esa lectura de la gobernabilidad es pertinente, puesto que de lo que se trata es de reflexionar sobre el impacto social —es decir, sobre la sociedad- de la crisis financiera mundial. Y es que las formas cómo las sociedades puedan reaccionar ante ese impacto abre las puertas a situaciones posibles de ingobernabilidad, esto es, a la emergencia de demandas sociales que desborden la capacidad de los Estados para darles respuesta. En el caso de Centroamérica —al igual que en el caso de otros países latinoamericanos - es indiscutible que existen actualmente otros factores de ingobernabilidad: por ejemplo, el crimen organizado, las mafias nacionales y regionales y las pandillas. Pero en lo que atañe al propósito de este ensayo --el impacto social de la crisis y sus implicaciones sociopolíticas - una de las formas posibles de leer ese impacto en clave de gobernabilidad o ingobernabilidad consiste en atender al modo cómo el movimiento social se ha posicionado en torno a la misma. Insistimos: es muy probable que existan otros factores que desafíen la gobernabilidad en Centroamérica, pero aquí nos interesan básicamente los que guardan relación con el impacto social de la crisis. Y es en ese marco en el que situamos las ideas que siguen a continuación, en torno al "rupturismo social".

\subsection{El rupturismo social: América Latina y Centroamérica}

En América Latina el rupturismo social ha sido alimentado fuertemente por situaciones de crisis económica — por ejemplo, la crisis de la deuda de los años ochentay se tradujo, ahí donde se dieron, en un severo cuestionamiento a los gobiernos por parte de amplios sectores sociales. Y es que como anota Andrés Benavente: en el contexto de la crisis económica, "se presentan agudos problemas sociales respecto de los cuales los gobiernos no son percibidos con capacidad para resolverlos, lo que afecta la capacidad de las instituciones. Esto da lugar a extendidas movilizaciones de protesta sin características ideológicas significativas que expresan más bien un estado de ánimo con mezcla de ira y frustración. Si los partidos políticos están afectados por una crisis de representatividad lo más probable es que se termine en una crisis de gobernabilidad" ${ }^{\prime 4}$. Es decir, las situaciones de rupturismo social no sólo son situaciones de crisis socio-política, sino de erosión de las identidades individuales y colectivas, con un fuerte componente de anomia, de desarraigo y, como dice Andrés Benavente, de "ira y frustración".

Distintos países latinoamericanos desembocaron, en los años noventa y principios del 2000, en situaciones de ingobernabilidad en las cuales una crisis económica jugó un papel decisivo: por ejemplo, Ecuador (1997), Paraguay (1999), Perú $(2001)^{5}$, Argentina 
(2001) y Bolivia (2003). Eso sucedió como culminación de movilizaciones sociales que, teñidas de prácticas violentas, no sólo desbordaron los cauces institucionales establecidos, sino que pusieron de manifiesto la incapacidad de los gobiernos para "manejar de manera eficiente escenarios interactivos, procurando un equilibrio entre factores diversos y no pocas veces contrapuestos" ${ }^{\prime \prime}$.

Esta fue la experiencia latinoamericana, cuya reseña tiene por fin ofrecer un marco para evaluar la situación centroamericana en estos momentos. $Y$ es que, en contraste con lo sucedido en el pasado reciente de algunos países latinoamericanos, para Centroamérica, en el marco de la actual crisis económica, vale más bien la primera tendencia, de las dos anotadas antes: la existencia de dinamismos socio-económicos y políticos que han diluido su impacto, y que, en consecuencia, han impedido que la misma se convierta en el catalizador de la inconformidad y el malestar que caracterizan a amplios sectores de las sociedades centroamericanas.

Quizás, en el marco de la crisis actual, es México el país en el que es más claro el papel que está jugando la crisis económica como catalizadora del malestar social y político prevaleciente. De hecho, los sindicatos mexicanos anunciaron, a mediados de octubre de este año, la realización de una huelga general en respuesta a la crisis económica. Y un mes antes, Fabiola
Alanis, dirigente estatal del Partido de la Revolución Democrática (PRD) había augurado que habría fuertes movilizaciones en contra del gobierno federal. Asimismo, la dirigente del PRD comentó que era previsible que los sindicatos se manifestaran de manera organizada debido a los efectos de la crisis en el ámbito laboral y por la pérdida de poder adquisitivo de los salarios. La perredista detalló que la gente está desesperada, luego de la crisis económica que "estamos padeciendo desde hace meses. Por ello es de esperarse que haya movilizaciones en todo el país, debido a la mala actuación de la Federación" ${ }^{\prime 7}$.

Sería largo explicar las razones por las cuales en México las cosas están evolucionando de esa manera. Sin duda, pesa sobremanera la fortaleza del sindicalismo mexicano; un sindicalismo que se desarrolló al amparo del PRI y que ahora, sin muchos de los respaldos institucionales de los que gozó en el pasado, tiene que valerse de sus propios medios para ver cumplidas sus demandas. Y, en estos momentos, buena pare de esas demandas giran en torno al impacto de la crisis sobre el sector laboral mexicano.

Pero, volviendo a Centroamérica, aquí la crisis económica, como tal, no ha sido detonante de movilizaciones sociales amplias ni de rupturas socio-políticas que hayan puesto en vilo la estabilidad institucional de los países de la región. No hay constancia de que tal cosa haya sucedido en ninguno de los países 
centroamericanos, pese a la dureza con la que la crisis los ha golpeado. Ello no quiere decir, no obstante, que no haya habido reacciones sociales ante la crisis. Por supuesto que la ha habido, pero se ha tratado de respuestas puntuales - centradas en demandas de carácter sectorial: mantenimiento de subsidios, ayuda a quienes dejaron de percibir remesas del extranjero, creación de empleos, defensa del poder adquisitivo, Ilamados del sector empresarial para que los gobiernos le otorguen algún tipo de ayuda-, con poco calado en la marcha socio-política de mediano y largo plazo de los países de la región. Y ahí donde se insinuó la posibilidad de que el movimiento social centroamericano trascendiera hacia demandas de mayor incidencia socio-política, el diagnóstico que se hizo de la crisis no se tradujo en acciones concretas que presionaran a los gobiernos de manera efectiva.

Una de las primeras muestras de esto fue la "Declaración de la Asamblea de los Movimientos Sociales", fechada en enero 20098, la cual fue suscrita por distintas organizaciones sociales centroamericanas. Entre otras cosas, la "declaración" dice lo siguiente: "estamos ante una crisis global provocada por el capitalismo que no tiene salida dentro de este sistema. Todas las medidas adoptadas para salir de la crisis sólo buscan socializar las pérdidas para asegurar la supervivencia de un sistema basado en la privatización de sectores estratégi- cos de la economía, de los servicios públicos, de los recursos naturales y energéticos, la mercantilización de la vida y la explotación del trabajo y de la naturaleza, así como la transferencia de recursos de la periferia al centro y de los trabajadores y trabajadoras a la clase capitalista. Este sistema se rige por la explotación, la competencia exacerbada, la promoción del interés privado individual en detrimento del colectivo y la acumulación frenética de riqueza por un puñado de acaudalados...

Para hacer frente a esta crisis es necesario ir a la raíz de los problemas y avanzar los más rápidamente posible hacia la construcción de una alternativa radical que erradique el sistema capitalista y la dominación patriarcal. Es necesario construir una sociedad basada en la satisfacción de las necesidades sociales y el respeto de los derechos de la naturaleza, así como en la participación popular en un contexto de plenas libertades políticas. Es necesario garantizar la vigencia de todos los tratados internacionales sobre los derechos civiles, políticos, sociales y culturales (individuales y colectivos), que son indivisibles.

En este camino tenemos que luchar, impulsando la más amplia movilización popular, por una serie de medidas urgentes como: (a) la nacionalización de la banca sin indemnización y bajo control social; (b) reducción del tiempo de trabajo sin reducción del salario; (c) medidas para garantizar la soberanía alimentaria y energética; (d) poner 
fin a las guerras, retirar las tropas de ocupación y desmantelar las bases militares extranjeras; (e) reconocer la soberanía y autonomía de los pueblos, garantizando el derecho a la autodeterminación; (f) (garantizar el derecho a la tierra, territorio, trabajo, educación y salud para todas y todos; (g) y democratizar los medios de comunicación y de conocimiento" ${ }^{\prime \prime}$.

En Centroamérica, al menos hasta ahora, no se ha desencadenado una "amplia movilización popular" para forzar a los gobiernos del área al cumplimiento de las demandas propuestas en la declaración citada. Y algo semejante cabe decir en el caso específico de las organizaciones populares y movimientos sociales centroamericanos que se reunieron en Tegucigalpa, Honduras, en abril del 2009, en el marco de VII Ronda de negociación Unión Europea-Centroamérica. En la posición de estas organizaciones populares y movimientos sociales se puede leer, entre otras cosas, lo siguiente: "vemos como la crisis global tiene un impacto directo que sigue profundizando las condiciones de pobreza, exclusión, discriminación y marginación de nuestros pueblos, que se ha venido agravando con la entrada en vigencia del TLC con Estados Unidos y que nos ha hecho más dependientes de la economía de ese país, lo que provoca una mayor vulnerabilidad económica y pérdida de soberanía como pueblos y como región centroamericana. La crisis ha demostrado que el modelo neoliberal impuesto expresado a través de los tratados de libre comercio, ha fracasado y que se hace necesario encontrar nuevas alternativas privilegiando en opciones desde nuestras propias sociedades. Que busque más equidad, más solidaridad, justicia social y sostenibilidad ambiental".

Y se concluye así: "por el carácter excluyente de la negociación, por ser hasta ahora un acuerdo [Acuerdo de Asociación entre la Unión Europea y Centroamérica (AdA)] que beneficia únicamente a las transnacionales y al gran capital, [como] movimiento social centroamericano demandamos la inmediata suspensión del proceso negociador y el inicio de procesos de discusión, consulta y análisis en cada país, con la participación real y vinculante por parte de las organizaciones y movimientos sociales. Llamamos a impulsar una verdadera integración centroamericana desde las necesidades e intereses de los pueblos. Llamamos a todo el movimiento social Centroamericano a redoblar la presión y movilización social para garantizar relaciones comerciales justas y solidarias que no estén basadas en la lógica del libre comercio y que se promuevan un desarrollo sostenible, equitativo y de respeto mutuo" ${ }^{\prime 10}$.

Como puede verse, no se trata de un Ilamado a acciones relacionadas directamente con la crisis, sino con algo previo a ella. Pero lo grave no es eso, sino que ese llamado no se tradujo en presiones ni 
movilizaciones reales que obligaran a los gobiernos a hacerse cargo de las demandas que se plantearon en ese foro. Cabe cuestionarse por las razones de ello, es decir, por las razones que han impedido que el movimiento social centroamericano responda con energía al impacto de la crisis y convierta su presencia pública en una señal de alarma para los gobiernos y, más en general, para la institucionalidad vigente. ¿Cuáles son las razones posibles que han intervenido (e intervienen) para que ello sea así? Esto nos remite a la exploración de algunos de los condicionantes más importantes de los movimientos sociales en Centroamérica.

\subsection{Condicionantes del movimien- to social centroamericano}

Sin agotar los posibles condicionantes que permitirían entender el modo cómo el movimiento social ha encarado, en el plano de la práctica, el impacto de la crisis, es oportuno destacar tres de los más relevantes, que, obviamente, adquieren matices en el caso particular de cada país: (a) su profunda debilidad organizativa; (b) la confianza en los procesos políticos que se suscitaron en la región antes o durante la crisis; y (b) la presencia de dinamismos sociales que marcan de manera más firme la vida social que los efectos de la crisis.

(a) El movimiento social centroamericano. Obviamente, la situación (fortaleza o debilidad) del movimiento social de cada país — sin- dicatos, organizaciones comunales, asociaciones cooperativas, gremios, etc. - es distinta. A grandes rasgos, se puede decir que Nicaragua debido a la potenciación que tuvo la organización social durante la revolución sandinista y al escenario favorable para la misma con el retorno de Daniel Ortega al poder-y Costa Rica - debido al marco favorable para la organización social posibilitado por el peso de la clase media en la dinámica social costarricense y por la firme tradición socialdemócrata de sus instituciones políticas- son los países con un desarrollo más firme de su movimiento social en la región ${ }^{11}$. En lado opuesto, en términos relativos, están los demás países centroamericanos —El Salvador, Guatemala y Honduras- en los cuales, por su particular trayectoria histórica, el movimiento social acusa una fuerte debilidad en términos organizativos y de capacidad de presión. Panamá, por su lado, es un caso aparte del resto de Centroamérica: a su aparato económico anclado históricamente en los servicios, se añade una firme creencia popular (de un $83 \%$ ) de que la democracia es el mejor de los regímenes políticos existentes, pese al escepticismo reinante acerca del funcionamiento de la mayor parte de instituciones del país. Como señala Armando Ortuño, "en general, la democracia sigue siendo valorada positivamente por la mayoría de la población, pero hay una notoria frustración e insatisfacción respecto de sus resultados. La insatisfacción 
por el desempeño de la democracia en Panamá tiende a aumentar, incluso más allá de las coyunturas económicas específicas"12. En el marco de la actual crisis financiera, esa insatisfacción encontró un cauce en el proceso electoral que dio el triunfo al derechista Ricardo Martinelli, de Cambio democrático, sobre Balbina Herrera del PRD.

No se quiere decir que el movimiento social sea absolutamente inoperante o de una nula presencia, pero en los casos específicos de El Salvador y Guatemala pesa la desmembración sufrida por el movimiento social —sindicatos, organizaciones populares, asociaciones estudiantiles, gremios, universidades y grupos religiosos-, entre los años setenta y principios de los años noventa $^{13}$, debido a la fuerte represión militar y paramilitar. En los años ochenta e inicios de los noventa ambos países se desenvolvieron en un escenario de agudos conflictos militares internos - que en El Salvador cobraron el carácter formal de una guerra civil- los cuales diezmaron sensiblemente las energías del movimiento popular organizado. Finalizados esos conflictos en la primera mitad de la década de los noventa, mediante soluciones negociadas, el movimiento social comenzó a caminar cuesta arriba, en un escenario dominado por una lógica privatizadora — alentada por el arribo de gobiernos que asumieron expresamente la puesta en práctica de la agenda neoliberal inspirada en el consenso de Washington-que puso fuertes obstáculos al resurgimiento de un movimiento social sólido y con la capacidad suficiente para desafiar las élites empresariales y políticas.

Honduras, por su parte, si bien no atravesó por un conflicto militar interno semejante al que vivieron Guatemala y El Salvador, tampoco se ha caracterizado por poseer un movimiento social suficientemente amplio y organizado, como para hacer tambalear los cimientos del orden vigente. La dureza de la represión militar - junto con mecanismos de control social, político y cultural- impidió que, en los años sesenta y setenta, la sociedad hondureña desarrollara procesos de organización socio-política semejantes a los que se desarrollaban en Guatemala y El Salvador.

Esos procesos desembocaron, en estos dos países, en conflictos militares internos de gran envergadura. En Honduras eso no se dio. Y ahí donde esa posibilidad fue anunciada, el Estado militar hondureño —que en los años ochenta hizo de este país una plataforma de agresión estadounidense contra $\mathrm{Ni}$ caragua y de contención contra las guerrillas de El Salvador y Guatemala- respondió con contundencia, abortando de raíz cualquier desafío político-militar al orden establecido. Cuando finaliza el conflicto centroamericano, el movimiento social hondureño también debe caminar cuesta arriba, no para recuperar tradiciones organizativas del pasado, sino para crear, con lo poco 
que se tiene, formas organizativas que permitan encarar los desafíos que se le presentan a la sociedad hondureña en un contexto en el que viejos mecanismos de explotación (de tipo oligárquico) se mezclan con esquemas de explotación de modernos (enmarcados en la lógica neoliberal).

Hacia mediados del 2000 -que es cuando se comienzan a hacer evidentes las señales de agotamiento del programa neoliberal asumido en la década anterior- el movimiento social salvadoreño, guatemalteco y hondureño comienza a dar muestras de mayor fortaleza, aunque sin lograr articular plataformas de lucha que puedan ser sostenidas durante periodos prolongados de tiempo. $\mathrm{Ni}$ el rechazo al neoliberalismo o a los tratados de libre comercio, ni la resistencia a las empresas mineras o a los proyectos de construcción de presas hidroeléctricas, dan paso a amplias movilizaciones que, además de articular la dispersión de organizaciones existentes, sumen a otros actores sociales significativos y logren una continuidad temporal que vaya más allá de la protesta puntual, ya sea con motivo de una afrenta particular (presencia de una empresa minera en un territorio determinado) o la celebración de una fecha memorable (Día Internacional de los trabajadores o fiesta de Independencia).

El mejor ejemplo de las dificultades de los movimientos sociales de Honduras, El Salvador y Gua- temala para sostener demandas de envergadura fue el débil posicionamiento que se tuvo ante la suscripción, por los respectivos gobiernos, de tratados de libre comercio con Estados Unidos. Con la excepción de Costa Rica - país en el cual el proceso desembocó en un referéndum (en octubre 2007) - en el resto de naciones no hubo ni consultas serias a la sociedad por parte de las autoridades ni un movimiento oposición del lado de aquélla que fuera capaz de, al menos, modificar algunos de los aspectos de los tratados.

En este sentido, es ilustrativo lo sucedido en El Salvador, en donde "esa falta de participación de la sociedad civil se fue profundizando hasta llegar a la exclusión en las discusiones del TLC con Estados Unidos. Estas discusiones iniciaron en enero de 2003 y se prolongaron durante todo ese año, no obstante que el tratado fue ratificado hasta marzo de 2006. Ya desde el inicio de las negociaciones oficiales, el 8 de enero de 2003, se hizo presente una de las líneas de acción que el movimiento social seguiría de ahí en adelante hasta la firma del tratado: el rechazo de los tratados de libre comercio. En efecto, en la mañana de ese día sindicalistas y miembros de organizaciones ciudadanas bloquearon importantes calles de la capital y se tomaron la Catedral Metropolitana.

No se trató, sin embargo, del inicio de una dinámica de protestas y movilizaciones sostenida a lo largo del tiempo, sino de un brote 
esporádico de resistencia, de los cuales habría muchos a lo largo de 2003, 2004 y 2005. Más sostenido y sistemático fue el rechazo del FMLN a los TLC, pero esto se hizo desde el espacio legislativo y/o acompañando movilizaciones puntuales (por ejemplo, en el marco de las celebraciones de aniversario de Monseñor Romero o el día internacional del trabajo) en las que las voces de rechazo a los tratados de libre comercio se hacían sentir con fuerza. En la medida en que los sectores sociales más críticos se pusieron en contra del TLC con EEUU, los grupos empresariales más influyentes se coordinaron con los representantes del gobierno salvadoreño para dejar plasmados sus intereses en las distintas rondas de negociación previas a su firma. Este se tradujo en un énfasis exagerado en los aspectos económicos del tratado, quedando de lado aspectos sociales y políticos que eran esenciales para el conjunto de la sociedad salvadoreña"14.

A grandes rasgos, esta es la situación de Guatemala, El Salvador y Honduras — visto desde el lado de sus respectivos movimientos sociales - en el momento en el que la actual crisis económica golpea a los tres países. En conjunto, están en una situación que pone serias limitaciones a su capacidad de respuesta al impacto social de la crisis. ¿Y qué sucede en Nicaragua y Costa Rica, países con movimientos sociales más firmes? ¿Qué sucede en Panamá, en donde en los últimos años la firme creencia en la democracia se ha visto acompañada de una desconfianza en las instituciones? Pues bien, en ninguno de estos países se registran movilizaciones sociales masivas en respuesta al impacto de la crisis ni —lo que es más importante desde un punto de vista sociopolítico- desafíos abiertos a los gobiernos establecidos. $Y$ esto nos remite al segundo aspecto que queremos destacar como posible factor explicativo de la débil respuesta del movimiento social centroamericano ante el impacto de la crisis.

(b) Los procesos políticos. Se trata de procesos que no pueden dejarse de lado y que tiene que ver con los relevos que se operaron en los aparatos gubernamentales en los momentos previos a la crisis o cuando ésta estaba impactando a las naciones del área. Recordemos que, en Centroamérica y Panamá lo efectos de la crisis se comenzaron a sentir — no de una manera abrupta- desde finales del 2008, vaticinándose su mayor impacto hacia mediados del 2009 y, de ahí en adelante, incluso hasta el 2010, año en el cual —según algunas gremiales empresariales - la economía comenzaría a recuperarse.

Comenzando con el caso de Nicaragua, en 2006 fue electo como presidente de la República Daniel Ortega (del FSLN), quien supo capitalizar a su favor las bazas institucionales forjadas en los años previos, gracias al pacto Ortega-Alemán. Las elecciones en sí mismas se convirtieron en una 
oportunidad para que amplios sectores de la sociedad nicaragüense manifestaran su rechazo no sólo ante una conducción político-estatal caracterizada por elevadas cuotas de corrupción - a las que no fueron ajenos el FSLN y Ortega-, sino por el deterioro en sus condiciones de vida causado por una mala gestión de la economía, realizada en el marco de un programa neoliberal impulsado por los gobiernos que dirigieron al país desde 1990 hasta 2006.

De hecho, el triunfo electoral de Ortega fue leído por distintos sectores -quizás de un modo poco crítico-, dentro y fuera de Nicaragua, como "una derrota del neoliberalismo"15. No obstante, ello no quiere decir que la victoria de Ortega fuera abrumadora. En efecto, tal como lo reseñó la revista Envío: el Frente Sandinista ganó sin crecer. "Daniel Ortega ganó con un apoyo minoritario de la población. Y con la mayoría votando 'contra' él. En Nicaragua se puede ganar la Presidencia de la República con tan sólo un $35 \%$ de los votos, si se logra una diferencia del 5\% sobre el candidato del segundo lugar. Es una de las varias reformas electorales que se fraguaron en el pacto Ortega-Alemán de 1999. Anteriormente, era necesario el $45 \%$ para llegar a la Presidencia. Ortega ganó ahora con el 38\% de los votos. En las tres anteriores elecciones obtuvo porcentajes similares o mejores: en 1990 frente a doña Violeta de Chamorro, 41\%; en 1996 frente a Arnoldo Alemán, un 38\%; y en 2001, frente a Enrique Bolaños, un $42 \%$. A pesar de su costosísima campaña electoral y del organizado activismo de sus comandos electorales, además de su amplia política de alianzas — con somocistas, con ex-contras, con gremios, con Yátama en el Caribe- el FSLN apenas creció en unos 15 mil votos con relación a sus votantes del 2001. En Managua, su tradicional bastión, sus votos se redujeron del $44 \%$ en 2001 a un $36 \%$ en este $2006^{\prime \prime 16}$.

Según algunos analistas de la realidad nicaragüense, el pacto Ortega-Alemán también redituó beneficios para el sandinismo en las elecciones de noviembre de 2008 para alcaldes y consejos municipales en las cuales, entre otros éxitos del sandinismo, fue derrotado el empresario Eduardo Montealegre, en la competencia por conquistar de la alcaldía de Managua, por el candidato del FSLN, el ex boxeador Alexis Argüello. "Desde hace diez años - dice la Revista Envío- funciona el pacto Ortega-Alemán, cada vez más beneficioso a Ortega. El tribunal electoral, el CSE, fue afectado progresivamente por este acuerdo político. Al iniciar 2008, año electoral, el CSE fue colocando calculadamente en el camino a las elecciones obstáculos a los partidos opositores y pavimentándole la ruta al partido de gobierno. El CSE adelantó el calendario electoral, suspendió las elecciones en siete municipios del Caribe, canceló la personería jurídica a dos partidos opositores y 
le quitó la representación legal de ALN a Eduardo Montealegre para entregar esa agrupación a políticos colocados en la órbita del partido de gobierno. Todas estas medidas fueron maniobras preelectorales del pacto Ortega-Alemán. Como resultado de todas ellas —avaladas por acción o por omisión, por los magistrados pro-Alemán en el PLCtodo el Poder Electoral, desde las máximas autoridades hasta la dirección de las 11,808 juntas a donde acudieron a votar los nicaragüenses el domingo 9, quedaron prácticamente en manos de personas afines al partido de gobierno o controladas de una forma o de otra por éste" ${ }^{17}$.

De todos modos, el sandinismo tuvo un indudable ascenso político el cual alimentó en distintos sectores sociales - especialmente en los cercanos al partido- la percepción de que mediante el mismo se atacarían los males generados por los gobiernos anteriores. Ello explica, en buena medida, la ausencia de un movimiento social que, en respuesta a la crisis, pudiera haber desestabilizado el orden institucional vigente, planteando demandas que lo desbordaran.

Quizás con un gobierno de signo distinto $-\mathrm{y}$ al que los sectores más radicalizados de Nicaragua hubiesen concebido en continuidad con gestiones pasadas de signo neoliberal - la capacidad organizativa y las energías del movimiento social nicaragüense se hubieran volcado de lleno hacia las calles y plazas, creando un clima de inestabilidad y de ruptura social propias de una situación de ingobernabilidad. Pero con un gobierno considerado, al menos retóricamente, en sintonía con la inconformidad y el malestar populares, no era previsible que el mismo fuera desestabilizado por quienes lo veían, precisamente, como la alternativa a quienes eran considerados responsables de los males que aquejaban al país. Esta percepción de que el gobierno de Ortega constituía una alternativa a las gestiones neoliberales se vio reafirmada por un conjunto de políticas sociales que, gracias a una gama de donaciones y ayudas de distintas fuentes, así como de un vínculo firme con Venezuela, se pusieron en marcha una vez que nuevo gobierno comenzó su gestión. $Y$, una vez desencadenada la crisis, el gobierno diseñó, más que por presiones sociales, por propia iniciativa, un conjunto de medidas orientadas a atender los efectos sociales de la crisis, siendo una de las más llamativas el programa de abastecimiento alimentario, a través del financiamiento a los productores agropecuarios, propuesto a inicios del 2009.

Pese a que algunos analistas vaticinaban que - debido a la suspensión de ayudas millonarias provenientes de Estados Unidos y a la paralización de importantes créditos del Banco Interamericano de Desarrollo (BID), Banco Mundial (BM) y Fondo Monetario Internacional (FMI)—, no es "difícil que en 
Nicaragua, en los próximos meses efectivamente se desencadenen nuevas disputas intraburguesas, aunadas a la movilización de importantes franjas de la clase trabajadora que se vienen alineando ya sea tras el FSLN de Ortega, o tras la burguesía más recalcitrante que representa Montealegre"18, se llegó prácticamente al cierre del año 2009 sin que tal clima de inestabilidad socio-política se suscitara en esta nación. Todo parece indicar, en este sentido, que la percepción de amplios sectores sociales nicaragüenses acerca del gobierno no cambió de manera sensible durante los momentos en los que la crisis impactó de manera más fuerte al país. Queda en pie la pregunta sobre si, de prolongarse la crisis después del 2009, el gobierno de Ortega va a ser capaz de seguir manteniendo las políticas sociales que son las que, en definitiva, reafirman en el imaginario colectivo la idea de que se está ante una gestión gubernamental distinta, comprometida con la realización de cambios socio-económicos que beneficien a los sectores sociales más pobres y vulnerables de Nicaragua. O si, también, el gobierno de Ortega va a seguir siendo capaz de seguirse sosteniendo institucionalmente a partir de arreglos fundados en negociaciones no sólo ilegales, sino marcados por la corrupción.

Costa Rica, como se sabe, es el país que distingue no sólo de Nicaragua, sino del resto de países centroamericanos, por la firmeza de su democracia, por su sólido desarrollo institucional y por sus notables conquistas sociales, derivadas de un ejercicio estatal que apostó por el bienestar social en la década de los años cuarenta del siglo XX. Históricamente —concretamente desde que se implantó el modelo de bienestar en los años cuarenta-, el movimiento social costarricense no se ha caracterizado, pese a su fortaleza, por su carácter disruptivo; antes bien, sus derroteros organizativos y de participación han seguido los cauces legales-institucionales establecidos que, por lo demás, gozan de una legitimidad ampliamente reconocida y aceptada por los distintos sectores de la sociedad costarricense.

Es indiscutible que Costa Rica era el país que más preparado estaba a nivel socio-económico, pero también institucional y político, para hacer frente al impacto social de la crisis. Si es cierto que para que un movimiento social adquiera un carácter rupturista $-\mathrm{y}$ ponga a la sociedad al borde de la ingobernabilidad- el régimen político establecido tiene que ser percibido como carente de legitimidad, en Costa Rica esa legitimidad es una conquista histórica bien cimentada. De aquí que la elección por segunda vez de Óscar Arias como presidente de la República, lejos de ser un rechazo frontal a gobiernos pasados, fue la confirmación de una trayectoria histórica en la que se confía y de la cual Arias es una figura emblemática. 
Es por ello que, en su programa electoral, Arias hizo hincapié en la recuperación por una ciudadanía desencantada de la confianza en sus gobernantes y de la ilusión en seguir avanzando por la senda del progreso económico y social. Y su oferta se basaba en "ocho pilares fundamentales": luchar contra la corrupción, luchar contra la pobreza —padecida por el 18\% de la población, con todo una tasa muy baja para lo que es habitual en la región- y la desigualdad, crear "empleos de calidad" mediante la "integración en el mundo", sentar las bases de una "educación para el siglo XXI", luchar contra la delincuencia y las drogas, "poner en orden las prioridades del Estado", "recuperar la infraestructura" y "ennoblecer nuestra política exterior". El Gobierno desarrollaría cinco grandes políticas, social, productiva, exterior, de sostenibilidad ambiental y de reforma del marco jurídico-político, para conformar una Costa Rica "más progresista y enrumbada hacia la vía correcta del desarrollo"19. Asimismo, desde las filas de PLN —el partido de Arias-, se aseguraba que la suya era una "propuesta socialdemócrata renovada", y precisaba: "una socialdemocracia moderna es la que comprende que la disciplina macroeconómica, el control del gasto público, la deuda pública y la inflación no son el fruto de una delirante conspiración neoliberal, sino el legado de numerosos episodios de populismo macroeconómico en toda América Latina, que empobre- cieron a los más pobres mucho más que cualquier privatización". La política macroeconómica de Arias estaría "al servicio de los ciudadanos" porque perseguía acelerar el crecimiento económico - pasando del $4 \%$ registrado en 2005 a una tasa anual de entre el $6 \%$ y el $7 \%-y$ distribuir equitativamente los beneficios del mismo, lo que a la hora de gobernar implicaría una política monetaria de defensa del colón para reducir la inflación - superior al $13 \%$ anual, el índice más alto de la región-y proteger el poder adquisitivo de la población, y una política fiscal dirigida a reducir el déficit sin dejar de aumentar el gasto social, lo que necesariamente pasaría por incrementar la recaudación tributaria, haciendo "pagar más a quien más tiene ${ }^{\prime 20}$.

Así, del triunfo de Arias no se puede decir lo que se dijo del triunfo de Ortega: que fue una derrota del neoliberalismo ${ }^{21}$. Y ello porque, por las razones apuntadas, los embates del neoliberalismo - que en el resto de países centroamericanos se superpusieron a exclusiones estructurales heredadas del pasado- en Costa Rica fueron y han sido en términos relativos menos severos, lo cual no quiere decir que para algunos sectores costarricenses no se tratara de algo grave ${ }^{22}$. Pero un balance global de los años noventa, como el realizado por Edelberto Torres Rivas, deja en buen pie a Costa Rica. "La situación de la pobreza e indigencia en Centroamérica — dice este autor- muestra diferencias en magni- 
tud y evolución en los últimos años. Los niveles de pobreza, salvo Costa Rica, son extremadamente altos. La información disponible prueba que Guatemala, Honduras y Nicaragua tienen los niveles más altos en América Latina. Durante los noventa con el regreso del crecimiento económico se esperaba una reducción de la pobreza y la indigencia, que sólo se logró en Costa Rica por el papel activo del Estado que rebajó la magnitud de la pobreza" ${ }^{\prime 23}$.

Por su parte, sectores críticos acusaron a Arias - en el marco de la campaña que desembocó en las elecciones de 2006- de ser partidario de las políticas neoliberales — de hecho, se lo considera uno de los responsables de haber impulsado la agenda neoliberal en su primer mandato (1986-1990)_, mientras que su rival político, Ottón Solís, del Partido Acción Ciudadana (PAC), fue visto como alguien que cuestionaba abiertamente el sistema económico imperante en el país y que prefería que el Estado conserve estas empresas y propone una renegociación del TLC para corregir aspectos que podrían afectar a los productores nacionales ${ }^{24}$.

En Costa Rica, pues, el impacto de la crisis no ha desencadenado movilizaciones sociales que desafiaran la institucionalidad vigente, y ello debido, por un lado, al relativo menor impacto de la misma sobre la sociedad costarricense; $y$, por otro, debido a la legitimidad de su sistema político. Dicho de otro modo, el movimiento social costarricense durante décadas no se ha visto en la necesidad de desbordar los marcos institucionales existentes, en parte porque los mismos ofrecen un amplio marco para procesar las demandas sociales y en parte porque desde el Estado se han garantizado los resguardos necesarios para asegurar derechos económicos y sociales que permiten hacer frente situaciones adversas como la crisis actualmente en curso.

En lo que se refiere a Panamá, las elecciones de mayo - y el desplazamiento del poder del PRDtampoco —al igual que en Costa Rica- no expresaron un condena al neoliberalismo por parte de los sectores sociales que dieron su apoyo a Martinelli, sino más bien un castigo a un proyecto partidario el del PRD—, así como a quien no supo cumplir con las expectativas ciudadanas respecto del combate de la corrupción, la ineficiencia institucional y la incapacidad de gestionar conflictos. Hacia el año 2006, diferentes "líderes y dirigentes entrevistados plantean... que la corrupción es en sí misma uno de los problemas centrales de Panamá, y una de las causas del fracaso de las políticas públicas que ponen un freno al desarrollo del país... Otro elemento de insatisfacción está relacionado con la capacidad del Estado para responder a las demandas sociales y asumir un papel más proactivo en el desarrollo nacional. Sin embargo, las personas entrevistadas señalaron tres ideas sobre las fortalezas actuales de la 
institucionalidad estatal panameña: 1) el Estado no está desprovisto de recursos; 2) se asienta en la legitimidad y no en la imposición, es decir que los panameños reconocerían el valor de las instituciones, y el Estado habría sido tradicionalmente permeable a sus exigencias y planteos, y 3) tratándose de un Estado centralista en un país con poca población y dimensiones reducidas, éste tendría mayores ventajas para poner en práctica sus decisiones. La segunda afirmación, no obstante, tiende a ser puesta en duda por una parte importante de la opinión pública. Al mismo tiempo, se le reconocen importantes debilidades: 1) ineficiencia y falta de ejecutividad; 2) prácticas clientelares y la corrupción; 3) su excesiva injerencia en la marcha de ciertos sectores de la economía, y 4) ausencia de un liderazgo fuerte... En resumen, si bien no hay elementos que indiquen la presencia de una crisis generalizada del sistema político, existen importantes insatisfacciones y frustraciones, y un consenso generalizado acerca de que las instituciones públicas precisan transformaciones urgentes para aumentar su eficiencia y transparencia" 25 .

La crisis estalló y, sin embargo, esas "insatisfacciones" y "frustraciones" no se tradujeron en una oleada de protestas sociales que desestabilizaran al gobierno panameño y crearan una situación de "rupturismo social". Más bien, la sociedad panameña decidió seguir los cauces institucionales para "cas- tigar" electoralmente a un gobierno (y al partido que lo sostenía) que no había respondido a las expectativas ciudadanas, sobre todo en la segunda mitad de su mandato. $Y$ es que en sus primeros dos años de gestión, el gobierno de Martín Torrijos (2004-2009) Ilegó a contar con un $67.2 \%$ de aprobación popular ${ }^{26}$.

Es indiscutible que los panameños y panameñas esperaban mucho de Martín Torrijos: de algún modo, él conectaba el presente del país con los mejores logros del pasado, cuando su padre Omar Torrijos gobernó Panamá (desde 1972 hasta su muerte trágica en 1981), estableciendo las bases de la modernización y la democratización nacionales. Luego de la muerte de Torrijos cayó sobre Panamá una larga noche de violencia, corrupción y abusos cuya cara más visible fue Manuel Antonio Noriega (La "Piña" Noriega), desplazado del poder en 1989 por Estados Unidos, en el marco de una invasión — denominada "Operación causa Justa" - a Panamá. No fue fácil que los ciudadanos de este país se repusieran del impacto de la invasión, sobre todo cuando lo que vino después de ella fueron gobiernos (Guillemo Endara, Ernesto Pérez Balladares, Mireya Moscoso) en los que se incubaron males que dieron pie a la insatisfacción social. De aquí que Martín Torrijos pudiera capitalizar a su favor no sólo la memoria de su padre, sino el malestar social acumulado después de la invasión estadounidense. Al no ser capaz, 
durante su mandato, de responder a las expectativas sociales en torno a los problemas identificados como más graves, su partido fue relevado del poder, confirmando una tendencia a la alternancia política iniciada desde la salida de Noriega, sólo que esta vez ya no fue entre el PRD y el partido Arnulfista, sino entre el PRD y Cambio Democrático ${ }^{27}$.

En Nicaragua, para insistir en su contraste con Costa Rica, el movimiento social ha contenido sus reacciones ante el impacto de la crisis no por un (relativamente) débil impacto sobre la sociedad o por la legitimidad histórica de su sistema político, sino porque se espera que Daniel Ortega gobierne de manera diametralmente opuesta a como lo hicieron sus predecesores. De no hacerlo, corre el riesgo de enfrentarse a desbordes sociales impredecibles. En este sentido, la situación de Nicaragua no sólo ante el desenlace de la crisis, sino ante otros fenómenos que afecten a la sociedad es, comparada con Costa Rica, potencialmente explosiva.

Lo sucedido en Nicaragua -es decir, desactivación, gracias al arribo de un gobierno que gozaba de legitimidad popular, de desbordes sociales generalizados en respuesta a la crisis- también sucedió, con las especificidades de cada caso, en los países del Triángulo Norte: Guatemala, Honduras y El Salvador. En el primero de los tres países se realizó, en 2007, un proceso electoral que dio el triunfo a Álvaro Colom, quien asumió la conducción del
Ejecutivo guatemalteco en enero de 2008. Colom, de trayectoria socialdemócrata, derrotó —en segunda vuelta- al general retirado Otto Pérez Molina, ligado a los círculos de derecha de su país. Su triunfo, más que significar un rechazo al neoliberalismo, fue leído por amplios sectores de la sociedad guatemalteca como una posibilidad —una esperanza- de que los males endémicos de Guatemala podían ser enfrentados de una manera distinta.

La Unión Nacional de la Esperanza (UNE), el partido de Colom, se constituyó, en 2001, con la finalidad de trabajar por la erradicación de las graves desigualdades existentes, socio-económicas y étnicas, corrupción, impunidad y violencia generalizada. Y el principal lema de la campaña de Colom fue "la lucha contra la inseguridad, mientras que en el plano económico se comprometió a no crear ningún impuesto nuevo, reducir la tasa del Impuesto Sobre la Renta y aplicar 17 políticas económicas y 104 acciones concretas, establecidas en su plan de gobierno. Se dijo partidario de la creación de una Comisión Internacional contra la Impunidad (CIClG) en su país, promovida por el Gobierno"28.

No se trataba, en lo absoluto, de una plataforma radical, sino más bien de una plataforma moderada, que proponía atacar algunos de los graves problemas de la sociedad guatemalteca, pero sin alterar los fundamentos del poder económico, militar y político. No obstante su 
carácter progresista, el candidato de la UNE no obtuvo una victoria abrumadora sobre el candidato del Partido Patriota, el general Pérez Molina: Colom obtuvo el 52.23\% de los votos válidos en tanto que este último el $47.24 \%$. Estos resultados reflejan, de alguna manera, no sólo la desconfianza de amplios sectores de la sociedad guatemalteca hacia la institucionalidad política vigente, sino también los bajos niveles de participación ciudadana y el peso de una cultura política conservadora —-sostenida por una firme tradición autoritaria y por unos medios de comunicación obsequiosos con los grupos de poder- que introduce severas restricciones a la aceptación, por parte de sectores significativos de la sociedad, de cambios importantes en el orden vigente.

De todas formas, el arribo de Colom al Ejecutivo $-\mathrm{y}$ sobre todo, el impulso que este dio, desde que asumió su mandato, a importantes medidas de carácter social- fueron vistas por amplios sectores sociales como un alivio a una situación que, antes del impacto de la crisis, mostraba signos de un grave deterioro socio-económico. Justamente cuando la crisis comenzó a hacerse sentir en Guatemala, Colom tuvo un aliento de legitimidad popular ${ }^{29}$, al verse envuelto en un confuso hecho criminal -a raíz del cual resultó asesinado, en mayo, el abogado Rodrigo Rosenberg ${ }^{30}$ - que muchos interpretaron, especialmente el propio presidente guatemalteco, como una maniobra de la derecha para debilitar a un gobierno que estaba impulsando medidas que favorecían a los sectores sociales más vulnerables $^{31}$. La hambruna ${ }^{32}$ que golpeó con dureza a Guatemala, a mediados del $2009-y$ que sin haber sido generada por la crisis, se ha visto agudizada por ella-, encontró a un gobierno aun con la capacidad de resistir movilizaciones sociales que, expresando una insatisfacción con su gestión, lo desafiaran con desbordes incontrolables ${ }^{33}$. Queda en pie la pregunta de cuánto va a ser capaz de mantenerse el gobierno sin verse acorralado la irrupción popular en las calles, si la hambruna se profundiza y los efectos de la crisis le impiden atender no sólo el problema de la crisis alimentaria, sino otros graves problemas sociales que padece Guatemala.

En Honduras - como se destacó arriba- también el impacto de la crisis se suscitó ante un gobierno que si bien ya estaba a mitad de su mandato - Manuel Zelaya asumió la presidencia en enero de 2006 y en diciembre de 2009 se celebrarían elecciones en las que se elegiría a un nuevo presidente de la República- había impreso un giro progresista en la conducción gubernamental, lo cual lo hacía gozar de una importante cuota de legitimidad popular cuando la crisis comenzó a impactar a la sociedad hondureña. Este giro fue particularmente significativo para los sectores críticos de la sociedad hondureña, porque Zelaya era una figura proveniente 
de los círculos de poder de la derecha oligárquica y su partido, el Liberal, uno de los dos partidos tradicionales de Honduras (el otro es el Nacional) ${ }^{34}$. Al momento de ser elegido no representó lo que Álvaro Colom en Guatemala -ni mucho menos, lo que representó Ortega en Nicaragua - sino la confirmación de un ejercicio político rutinario, en el cual la competencia entre los partidos Liberal y Nacional reacomodaban sus posiciones y las de los grupos de interés que estaban detrás de ellos. "Terrateniente, vástago de una de esas familias que siempre han dominado la vida política de Honduras y miembro de un partido de orden": así era visto Zelaya antes de asumir el poder e incluso durante los dos primeros años de su gestión presidencial.

Sin embargo, pasados casi dos años, el presidente hondureño comenzó a hacer cosas que no estaban en el libreto de los grupos de poder a los que él pertenecía (y pertenece). Sin presiones sociales significativas, prácticamente "desde arriba", Zelaya no sólo se hace cargo de graves problemas socioeconómicos de los hondureños y hondureñas, a los que intenta dar respuesta con medidas de política social y económica, sino que inscribe sus decisiones en un viraje político e ideológico que le generó la animadversión absoluta de sus hasta entonces compañeros y aliados en la política y los negocios. Esta animadversión se tradujo en una conspiración que desembocó, a finales de junio de 2009, en un golpe de Estado en contra de Zelaya. El periódico español $A B C$ describe así este proceso de ruptura y su desenlace con el golpe de Estado ${ }^{35}$ contra el presidente Constitucional de Honduras:

"Los dos primeros años de Zelaya en el poder transcurren sin demasiados sobresaltos, aunque el mandatario comienza a distanciarse de los poderes públicos, incluidos sus compañeros de partido, y de la oligarquía financiera del país. La sorpresa llega en agosto de 2008, cuando Honduras ingresa en la actual Alianza Bolivariana para las Américas (ALBA). Lo que al principio parecía una frivolidad destinada a obtener petróleo venezolano a buen precio devino en una deriva populista por parte de Zelaya.

La ruptura del mandatario con sus correligionarios liberales llega ese mismo año, cuando ha de decidirse el candidato a la Presidencia en las elecciones de noviembre de 2009. Zelaya apoya a la canciller Patricia Rodas, mediante la plataforma Poder Ciudadano. Según sus detractores, ella sería una marioneta en manos de Zelaya para reformar la Constitución y permitir su reelección en la siguiente legislatura. 
El partido, en cambio, sostiene a [Roberto] Micheletti, quien consigue derogar las leyes que impedían su postulación. Pero las internas dan como vencedor al vicepresidente, Elvin Santos.

La peleada elección de magistrados de la Corte Suprema de Justicia impedirá la ansiada reforma constitucional, por lo que Zelaya se lanza a la campaña de la "cuarta urna»: someter a consulta popular la posibilidad de votar, junto a presidente, legisladores y alcaldes, la convocatoria de Cortes constituyentes. La pregunta sería: "¿Está usted de acuerdo que en las elecciones generales de noviembre de 2009 se instale una cuarta urna para decidir sobre la convocatoria a una Asamblea Nacional Constituyente que apruebe una Constitución política?»

La oposición denuncia el desvío de recursos públicos para sufragar la iniciativa (Zelaya no ha presentado en 2009 los presupuestos generales) y, para frenar la estrategia, se decreta una ley parlamentaria por la que se impide convocar referendos en año electoral durante los seis meses anteriores a la fecha de celebración de los comicios.

Zelaya sigue en sus trece, o en su cuarta, y, apoyado por organizaciones sindicales, estudiantiles e indigenistas, reclama el derecho del pueblo a hacer oír su voz. Enfrentado también a la Corte Suprema, al Tribunal Electoral y a las iglesias cristianas, ordena al jefe de las Fuerzas Armadas, Romeo Vásquez, que distribuya el material electoral. Éste se niega (en marzo ya le advirtió de que los militares no se prestarían a un "autogolpe» manejado desde el poder) y es destituido, pero antes saca los tanques a la calle "para evitar incidentes». Acompañado de una turba de seguidores, Zelaya marcha hacia una base aérea para recoger urnas y papeletas y se atrinchera con ellas en la Casa Presidencial. Alli permanecerá protegido por una suerte de "ejército de Pancho Villa» compuesto por taxistas, parturientas y espontáneos cantantes folclóricos.

Insiste en que la consulta no es vinculante, que sólo es una sugerencia que después enviará al Congreso para su estudio. De la limpieza del proceso caben serias dudas, pues era el Ejecutivo el que convocaba y organizaba la consulta, el que escrutaría después los votos y el que habría de proclamar los resultados. Sólo los grupos afines al gobernante 
parecieron interesados en seguirle el juego, a pesar de que muchos funcionarios públicos denunciaron amenazas de despido si no secundaban la convocatoria.

Así las cosas, Zelaya mantuvo su particular cita con las urnas para el domingo. El sábado, bien entrada la noche, abandona la Casa Presidencial para pernoctar en su residencia de la colonia Tres Caminos. Después de tres días de tensión institucional, el Ejército se había retirado de las calles. Pero, de madrugada, dos centenares de soldados se presentan en su casa $y$, tras enfrentarse con su guardia personal, lo encañonan para, descalzo y en pijama, conducirlo a un avión militar y trasladarlo a Costa Rica"36.

No es plausible suponer que, de no haberse producido ese golpe de Estado, el gobierno de Zelaya hubiera enfrentado movimientos de protesta social ya fuera por el impacto de la crisis o por otros motivos. Y es que, desde que impulsó el viraje que se hizo referencia líneas arriba, su legitimidad entre los sectores populares comenzó a crecer - de forma paralela a como comenzó a ser descalificado por sectores de derecha y sectores militares. Como quiera que sea, lo que es indiscutible es que a partir del golpe de Estado la dinámica socio-política de Honduras cambió drásticamente no sólo respecto de su trayectoria anterior, sino en relación al resto de países centroamericanos. El impacto de la crisis $-y$ cualquier reacción social y política ante la misma- se vio diluido por este acontecimiento político que, desde que se dio, se convirtió en el eje principal de las preocupaciones de los hondureños y en tema central debate sociopolítico no sólo dentro de Honduras sino a nivel Centroamericano y Latinoamericano.
El golpe de Estado activó un importante movimiento social de resistencia en apoyo al retorno de Manuel Zelaya a la presidencia, al igual que puso en las calles, además de militares y policías para contener las protestas a favor de Zelaya, a simpatizantes de los golpistas. A medida que el tiempo ha ido pasando y que el retorno del presidente Zelaya se ha ido postergando, la violencia en contra del movimiento de resistencia se ha incrementado, poniendo a Honduras más que al borde de la ingobernabilidad al borde de una guerra civil. En un contexto con estas características, las energías ciudadanas se han encauzado hacia la solución de un problema percibido - no sin razón- como de mayores proporciones que el impacto de la crisis. Mientras el mismo no se resuelva, difícilmente la sociedad hondureña —al igual que la clase política- va a prestar la atención debida a otros graves problemas que, seguramente, cuando se salga de la crisis política, habrán empeorado. 
Es inevitable no referirse, a propósito del golpe de Estado en Honduras, a la inoperancia de los organismos regionales y a la necesidad de su redefinición. El caso más Ilamativo es del OEA, cuya intervención en el la crisis hondureña fue, en la práctica, ineficaz, en tanto que sus recomendaciones y caminos de solución fueron desestimados primero por los golpistas y después por el presidente Zelaya. Otras instancias - como el PARLACEN o el SICA - tuvieron poco que decir (o no dijeron ni hicieron nada) en una situación que, además de poner en juego logros democráticos arduamente alcanzados, ha añadido un obstáculo más al propósito de avanzar hacia una integración económica regional.

Finalmente, tenemos el caso de El Salvador. En este país se realizaron dos eventos electorales en 2009, el primero - en eneropara elegir diputados y concejos municipales y el segundo -en marzo-para elegir al presidente de la República. Este segundo evento electoral coincidió con los primeros efectos sensibles de la crisis y la toma de posesión del nuevo presidente, el 1 de junio de 2009, con el desencadenamiento de sus efectos económicos y sociales más severos. La elección presidencial se revistió de un significado particularmente importante: el triunfo electoral de un candidato -Mauricio Funes - perteneciente a un partido de izquierda, que antes de convertirse en partido - a raíz de los Acuerdos de Paz de 19992había sido un poderoso ejército guerrillero. El ascenso político de Funes - un reconocido periodistay su victoria -que fue asimismo una victoria del FMLN-, pese a no haber sido abrumadora, expresaba una inconformidad cada vez más generalizada, entre amplios sectores de la sociedad - a nivel popular y en la clase media, pero también en determinados grupos empresariales - ante dos décadas de gestiones presidenciales de ARENA ${ }^{37}$. A excepción de los votantes duros del FMLN, para los cuales la derrota electoral de ARENA era expresión de un rechazo al modelo de capitalismo neoliberal del cual ese partido había sido un defensor acérrimo, para un amplio número de simpatizantes de la fórmula Funes-FMLN lo que estaba en juego era el relevo de un partido que en 20 años al frente del Ejecutivo lo había gestionado de manera inadecuada, generando exclusiones sociales de todo tipo y favoreciendo a un grupo reducido de empresarios que prosperaron bajo el amparo de los gobiernos de ARENA.

No se sabe que hubiera pasado en El Salvador, en materia gobernabilidad, si ARENA hubiera ganado nuevamente las elecciones presidenciales. Es probable que el impacto social de la crisis hubiese movilizado a sectores desafectos al (posible) gobierno de ARENA, pero quizás el problema mayor que habría enfrentado esa administración es el de el déficit de las finanzas pú- 
blicas que si bien no ha sido provocado por la crisis - pues tiene que ver con el mal manejo que se ha hecho de los recursos financieros del Estado y con falencias propias de la estructura tributaria vigente-, esta última terminó por agudizar. En un contexto así, un gobierno de ARENA difícilmente hubiera podido evitar protestas y movilizaciones populares, de las cuales, sin embargo, no puede asegurarse -a juzgar por el comportamiento del movimiento social en la postguerra - que habrían creado un clima de ruptura social y, en consecuencia, de ingobernabilidad. De todos, la posibilidad de que el movimiento social desbordara los cauces institucionales con protestas disruptivas fue contenida por el arribo al Ejecutivo de un gobierno de izquierda, justamente cuando los efectos sociales de la crisis se hacían sentir con más fuerza.

Es a este nuevo gobierno al que le ha tocado "administrar la crisis", tanto desde el punto de vista estrictamente económico -lo cual lo ha sometido a las presiones de los sectores empresariales que han reclamado medidas de rescate para sus empresas- como desde el punto de vista social. Y el gobierno de Funes ha tenido que hacerlo sin solvencia financiera - debido al elevado déficit fiscal que le tocó en suerte heredar de administraciones anteriores-, pero con una importante cuota de legitimidad popular - y entre importantes sectores de la clase media-que comenzó a crecer mucho antes de las elecciones - prácticamente desde la nomina- ción de Funes como candidato por el FMLN, a finales de 2007- hasta sus primeros 100 días de gobierno, a principios de septiembre de $2009^{38}$.

Si se fija la atención en los efectos sociales de la crisis, el gobierno de Funes - por lo menos hasta octubre de 2009- pudo encajarlos bastante bien, en el sentido de no haber enfrentado demandas de calle sistemáticas -aunque sí presiones de las gremiales empresariales-, sostenidas en el tiempo y con dosis de violencia significativa que amenazaran la estabilidad socio-política del país. En buena medida, ello se debió a legitimidad obtenida como el primer gobierno de izquierda en la historia de El Salvador, pero también a relativa solidez de la alianza socio-políticas que llevó a Funes al Ejecutivo: la establecida con el FMLN y los "Amigos de Mauricio". Cuánto durará esa legitimidad popular depende no sólo de cómo el gobierno de Funes encare los problemas sociales más graves del país —que no son exclusiva ni principalmente los generados por la crisis financiera mundial—, sino de la capacidad de mantener, más allá de las diferencias inevitables, un vínculo firme con el FMLN, que por su trayectoria histórica es, en sí mismo, una fuente importante de legitimidad popular para Funes y su gobierno.

Algunas señales preocupantes de que ese vínculo se estaba erosionando hicieron su aparición intermitentemente un par de meses 
después de que Funes asumiera la presidencia de la República; esas señales fueron más evidentes cuando, en octubre, el Coordinador del FMLN, Medardo González, afirmó que su partido había ganado las elecciones, pero no era el partido que gobernaba. En esa misma ocasión, González sostuvo que "de hecho con Mauricio somos una alianza, todo mundo sabe que Mauricio no es un militante histórico del FMLN, ese nunca fue problema ni va a ser problema. Somos un gobierno de alianza. Podrá llegar a ser, si el pueblo así lo considera mayoritariamente y nos da su voto, que el próximo presidente de la República sea un militante del FMLN. Ahí viene el tema. Independientemente de si sea militante o no, nosotros tenemos una claridad: todo funcionario tiene el compromiso de cumplirle al pueblo de acuerdo con el mandato de la Constitución de la República. Nosotros no asumimos, cuando asumimos un cargo de responsabilidad, el mandato de defender el interés del partido, sino lo que la ley nos manda, lo que la Constitución nos manda. El funcionario del FMLN trata de cumplir esa responsabilidad. Aquel funcionario que haga lo contrario, o que haga a desgano su trabajo, pues es normal que se busque la manera de removerlo. Lo que estoy diciendo es que el partido sí debe estar vigilante que desde el gobierno se apliquen bien las políticas" ${ }^{\prime 39}$.

La posibilidad de ruptura entre el FMLN y el gobierno de Funes que se manifiesta en esas palabras - o por lo menos de un distanciamiento entre ambos- da que pensar acerca de la fortaleza política del presidente de la República de cara a impulsar las reformas socio-económicas con las que se comprometió durante la campaña y las cuales le granjearon el respaldo popular que lo llevó al Ejecutivo ${ }^{40}$. Seguramente, un alejamiento del FMLN acercaría más a Funes a un sector de los "Amigos de Mauricio" -mismo que ahora tiene una fuerte presencia en el gobierno- y a los sectores empresariales más influyentes, por la sencilla razón de que, en caso contrario, se quedaría solo. $Y$, en un escenario así, la única forma de que la legitimidad obtenida el 15 de marzo no colapsase consistiría en implementar políticas sociales con resultados palpables para los sectores mayoritarios del país. El problema es que en un marco de acción gubernamental condicionado por los grupos empresariales no se ve cómo -y las experiencias tenidas con los cuatro gobierno de ARENA son aleccionadoras al respecto- se va a dar la prioridad debida a las necesidades y demandas sociales más urgentes.

Asimismo, el gobierno de Funes tiene desafíos urgentes que enfrentar y para lo cual necesita, principalmente, del respaldo de su partido, pero también del respaldo de otros actores socio-políticos. Uno de esos desafíos es el que plantea la violencia criminal, que no sólo tiene que ver con las pandillas, sino con el 
crimen organizado cuya operatividad desborda las fronteras salvadoreñas. Una respuesta inmediata a ese desafío ha sido la decisión sacar a la calle a la Fuerza Armada, para que apoye a la Policía Nacional Civil (PNC) en tareas de seguridad pública. Se trata de una decisión controversial, especialmente porque desde el FMLN -en momentos en que gobernaba ARENA - siempre hubo oposición a una medida de esa naturaleza. Sin embargo, las urgencias que plantea la propagación del crimen —su territorializaciònhacen comprensible la decisión del presidente Funes, al menos como una salida de corto plazo, que no impide avanzar en el fortalecimiento de las instituciones encargadas de perseguir y erradicar el crimen: la PNC y la Fiscalía General de la República.

Otro desafío impostergable es dotar al Estado de la necesaria solidez financiera. La precariedad fiscal no es nueva en El Salvador y siempre que se hizo evidente se recurrió - por lo menos en los últimos 20 años - a reformas fiscales que permitieran ampliar la base tributaria, conservando el esquema regresivo del sistema tributario. El gobierno de Funes ha logrado sacar adelante —a finales del 2009- una reforma fiscal en la que se insinúan tendencias hacia la progresividad fiscal, aunque de manera tibia. Las resistencias empresariales a esta última reforma fueron muchas y en su forcejeo con el gobierno de Funes estuvieron a punto de revertirla. De todas formas, la reforma se impuso, pero ha quedado claro que un cambio más drástico en la estructura tributaria —un cambio que la haga en verdad progresiva- dará lugar a enconadas batallas políticas.

Por último, el gobierno de Funes pudo salir adelante en su iniciativa de reforma fiscal gracias a una redefinición política inesperada: en octubre, ARENA sufrió una fractura interna, a resultas de la cual 12 diputados se separaron del partido y conformaron una agrupación denominada GANA. Sin dejar de ser de derecha, estos diputados no sólo se mostraron más abiertos a negociar sus votos con el FMLN, sino que forzaron a que los diputados de los otros partidos — principalmente, los del PCN — hicieran lo mismo. De pronto, una Asamblea Legislativa dominada por un bloque de derecha (ARENA, PCN y PDC) pasó a ser una Asamblea Legislativa en la cual, de hecho, se podía formar un bloque afín a la izquierda o, cuando menos, a algunas iniciativas suyas. Se trata de alianzas frágiles, marcadas por los acuerdos coyunturales (no de principio, sino pragmáticos), pero que han quitado presiones, desde la derecha, al gobierno de Funes: ARENA ha terminado el año enfrascado en sus conflictos internos - cuya última asonada fue la expulsión del ex presidente Antonio Saca-, con pocas energías para obstaculizar seriamente la gestión de Funes.

En resumen, en todos los países centroamericanos se suscitaron, 
en los momentos en los que crisis financiera comenzó a golpear a sus respectivas sociedades, procesos políticos que contribuyeron a atemperar —específicamente en Nicaragua, Honduras, Guatemala y El Salvador- posibles movilizaciones sociales que pudieron haberse suscitado, con distinta intensidad según cada país, como reacción al impacto de la crisis. Con todo, no sólo esos procesos contribuyeron a suavizar la reacción del movimiento social ante la crisis, sino que a ellos se sumaron otros dinamismos sociales cuya predominancia en el imaginario colectivo —-debido a su peso en la configuración de la convivencia social_ es más fuerte que impacto de algo más coyuntural como lo es la crisis y sus efectos sociales específicos.

c) Dinamismos sociales que marcan a las sociedades centroamericanas. Otro condicionante de la (débil) reacción de las sociedades centroamericanas - específicamente en Honduras, El Salvador, Guatemala y Nicaragua - tiene que ver con dinamismos y fenómenos que se suscitaron mucho antes de la crisis y que, por su fuerza y gravedad, configuran de manera decisiva $-y$ cotidiana- los comportamientos, actitudes y expectativas de la mayor parte de la sociedad.

Uno de ellos — sin duda importante- es la precariedad en la que viven amplios sectores de las sociedades centroamericanas, precariedad que tiene sus raíces en una situación de pobreza estructural que la transición de los años noventa no logró superar en sus aristas más hirientes ${ }^{41}$. En virtud de esa precariedad, en los sectores populares la preocupación esencial es cómo sobrevivir, lo cual hace que su cotidianidad esté dominada por actividades encaminadas a conseguir el sustento diario, dejando de lado (o prestando menos atención a) otras preocupaciones menos acuciantes. Cuando se superaron los conflictos, en la primera mitad de los años noventa, las reformas económicas que se implementaron en cada uno de los países del área no buscaban establecer condiciones de equidad y justicia social, sino propiciar el surgimiento de un nuevo modelo económico, del cual los principales beneficiarios serían los grupos de poder que fueran capaces de sacar provecho de las nuevas reglas de juego, es decir, los grupos de poder vinculados a las servicios financieros, el comercio, las maquilas $y$, en menor medida, el turismo. A las clases medias les "rebalsó" algo del crecimiento económico generado por las reformas neoliberales, con la creación de empleos en el sector servicios y, principalmente, con el otorgamiento de créditos que estimularan su consumo, en sintonía con la exigencias de la "terciarización" del modelo económico. Al cierre de los noventa, el bienestar de la clase media comenzó a irse a pique y en la siguiente década los agobios económicos — pago de deudas hipotecarias, crédito para compra de vehículos y tarjetas de crédito- la atraparon, marcando 
fuertemente sus preocupaciones cotidianas, ante las presiones también cotidianas - realizadas por los acreedores con el objeto de recuperar créditos otorgados, muchas veces con la mayor facilidad, cuando la situación de la clase media era más prometedora.

El impacto de la crisis agudizó esos agobios, pues añadió nuevas dificultades — pérdida de empleo, reducción de los ingresos, endurecimiento de las condiciones para conseguir nuevos créditos, imposibilidad de entregar (o vender) bienes recibidos mediante préstamos-, a las que ya se tenía para hacer frente a los compromisos económicos adquiridos previamente. Al igual que les sucedió a los sectores populares - que estaban ocupados en sobrevivir cuando la crisis se hizo presente-, sectores significativos de la clase media estaban ocupados en atender (y responder a) las presiones provenientes de unos acreedores que, a su vez, estaban cada vez más preocupados ante la posibilidad de no poder recuperar los créditos otorgados.

Pero eso no es todo. $Y$ es que desde mediados de los años noventa, con la excepción de Costa Rica y Panamá, los países centroamericanos incubaron distintas formas de violencia social que se hicieron cada vez más complejas y arraigadas a medida que el tiempo pasó y la respuesta estatal no estuvo a la altura del desafío representado por aquéllas. Las pandillas juveniles o "maras"42 constituyen la expresión más Ilamativa una problemática de violencia que vas más allá de ellas, pues involucra, además de la delincuencia común, al crimen organizado que ha extendido sus actividades - que van desde el narcotráfico, el tráfico de armas y el contrabando de vehículos hasta los secuestros, el tráfico de personas y la trata de blancas - por toda la región, México y sur América ${ }^{43}$. De hecho, esta violencia - especialmente, la asociada al crimen organizado-plantea un serio desafío a la gobernabilidad de los países del área, al grado de que sus desbordes crecientes han puesto en jaque no sólo la capacidad de los estados para contenerlos - y para responder a las demandas de seguridad que plantean los ciudadanos y ciudadanas-, sino también su legitimidad como garantes de la ley y el orden. Pero esta violencia criminal no obedece a la actual crisis económica, sino que es previa a ella. Es probable que se haya agudizado en el marco de la actual crisis, pero es difícil probarlo concluyentemente. Lo que si es indiscutible es que en un estudio sobre las posibles causas de ingobernabilidad en Centroamérica y Panamá - muy distinto al presente ensayo - la violencia criminal no puede faltar, al igual que tampoco puede faltar un estudio de la corrupción, así como un análisis de la institucionalidad nacional y regional.

Por otra parte $-y$ siempre con el tema de la violencia- aunque no todos los sectores sociales están ex- 
puestos de la misma manera a sufrir los embates de algún tipo de violencia, una sensación de inseguridad generalizada se ha ido apoderando de las sociedades en las cuales, a una violencia real -ciertamente grave $^{44}$-, se ha añadido una violencia construida ${ }^{45}$ por unos medios de comunicación que no sólo han inflado simbólicamente los niveles de violencia, sino que han propagado la tesis de la incapacidad de las autoridades - por ser poco duras y demasiado complacientes- para someter y dar su merecido castigo a quienes se ha terminado por identificar como los principales responsables de la violencia criminal: las maras.

En Guatemala, Honduras y El Salvador ha sido, a lo largo la presente década, particularmente acusada esta tendencia a la construcción simbólica de una violencia que ha exacerbado los temores y las incertidumbres acerca de los riesgos y las amenazas que se corren en plazas, calles, zonas y regiones identificadas como lugares en los cuales la propia integridad personal, además de los bienes personales, está en peligro inminente de ser violentada. Esos temores e incertidumbres se han traducido en pautas de comportamiento caracterizadas por la sospecha, la desconfianza hacia los desconocidos y la propensión creciente a buscar mecanismos de seguridad personal y familiar de los cuales nunca se tiene la certeza de que van a funcionar de manera plena. Cuando estos mecanismos comienzan a relajarse, siempre aparece el "hecho noticioso" (un crimen, un secuestro, un asalto) que los activa, a veces de manera drástica, como sucedió el 19 de octubre en El Salvador cuando la "noticia" de una presunta amenaza realizada por las pandillas — de que ese día habría un "toque de queda" en San Salvador- hizo que el pánico cundiera en la capital y que algunas centros de educación y negocios suspendieran sus actividades a partir de las 6 de la tarde ${ }^{46}$. Siempre en el caso de El Salvador son significativos algunos de los datos arrojados por una encuesta del IUDOP, de la UCA, cuyo objetivo era evaluar la percepción de inseguridad y establecer los niveles de victimización ${ }^{47}$. Según la encuesta, un $72.2 \%$ de la población entrevistada dijo haber creer que había aumentado en los últimos 5 años, mientras que, hablando de la posibilidad de ser víctima de la delincuencia, un $26.6 \%$ dijo sentirse inseguro en su lugar de residencia ${ }^{48}$.

Se entiende, entonces, que en sociedades atrapadas en la cárcel del miedo $-y$ con ciudadanos preocupados por sobrevivir y hacer frente a los agobios económicos inmediatos - el impacto de la crisis no haya ganado preponderancia, sino que más bien haya terminado por diluirse en el marco de dinamismos y procesos socio-políticos que están marcando de modo más decisivo a las sociedades centroamericanas y que condicionan fuertemente la vida ciudadana en general y, más 
en particular, a los movimientos sociales. El impacto de la crisis se ha añadido a un contexto socio-político conflictivo y violento, al igual que se ha añadido a una situación económica agobiante para los sectores populares y medios. Todo ello configura, en Guatemala, Honduras, El Salvador y Nicaragua, escenarios socio-políticos potencialmente ex- plosivos, cuyo desenlace efectivo dependerá no tanto de cómo se administre la crisis, sino de cómo se encaren los problemas estructurales y casi estructurales que caracterizan a estas a estas nacionales. Para hacer esto último se tienen que superar del mejor modo posible los efectos económicos y sociales de la crisis, pero no basta con ello.

\section{Reflexión final y postdata socio-cultural}

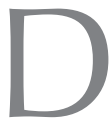
efinitivamente, la crisis financiera mundial tuvo un fuerte impacto económico en Centroamérica. Sin embargo, ese impacto no desencadenó respuestas sociales significativas que pusieran en vilo la estabilidad política de la región. Una serie de factores hizo de amortiguador de aquel impacto, frenando potenciales movimientos sociales de protesta que hubieran provocado un clima se ingobernabilidad en la línea del "rupturismo social". Con todo, no puede darse por descontada esa estabilidad $-y$ por tanto, la gobernabilidad- de la que gozan, en conjunto, los países de la región. Y es que las amenazas son muchas: violencia, crimen organizado, anomia, desarraigo y pobreza son, entre otros, elementos capaces de crear focos de inestabilidad que potencialmente pueden escapar (y en algunos casos ya lo hacen) del marco institucional, legal y coercitivo vigente, poniendo en jaque los ordenamientos estatales vigentes.
En otras palabras, las sociedades centroamericanas no están curadas del riesgo de la ingobernabilidad. Si bien el impacto de la crisis, en esta oportunidad, no fue un detonante lo suficientemente fuerte pare ello, en el futuro una crisis semejante sí puede serlo, a no ser que antes de ello la violencia o el crimen $-\mathrm{o}$ el malestar ante la pobreza y la exclusión - se confabulen para poner a nuestras sociedades en un escenario de caos y de violencia disruptiva.

En buena medida, para que ello suceda deben intervenir factores de carácter subjetivo --sostenidos por referentes y símbolos culturales- que alienten la rebeldía ante el orden establecido. En estos momentos, pese al impacto de la crisis y a la exclusión socio-económica heredada por dos décadas de neoliberalismo, no se vislumbra la vigencia de las condiciones subjetivas que sean la plataforma una rebelión social que lleve al caos y a la ingobernalilidad en las sociedades 
centroamericanas. Todavía pesan, en demasía, los valores culturales que promueven la búsqueda privada $-y$ privatizada - del bienestar personal, relegando a un plano muy secundario los compromisos colectivos. Sin duda alguna, la privatización cultural, neoliberal y globalizada - los valores, creencias y opciones fundadas en el éxito individual, el consumo exacerbado, el egoísmo posesivo y las marcas-, ha perdido todo sentido, ante una realidad social violenta y excluyente. Pero, casi por inercia, esa cultura sigue orientando las prácticas de amplios sectores sociales en Cen-

\section{Bibliografía}

Diego Achard y Manuel Flores. Gobernabilidad: un reportaje de América Latina. México, FCE-PNUD, 1997.

Patrick Ball, Paul Kobrak, Herbert F. Spirer, Violencia institucional en Guatemala, 1960-1998. Una reflexión Cuantitativa. Washington, American Asociation for the Advancement of Science, 1999.

Andrés Benavente U., "Estallidos sociales y escenarios de ingobernabilidad: consideraciones sobre el rupturismo social en América Latina". Ponencia presentada en el Seminario Internacional "Objetivos Estratégicos del Hemisferio para la próxima década". Marzo 2-4, 2006.

Brayan Brenes, "Centroamérica frente a una crisis histórica". Estrategia Internacional, No. 25, diciembre 2008-enero 2009. troamérica. Y no su relevo - por una cultura crítica, del compromiso colectivo, de la rebeldía- no llega, en parte quizás porque los llamados a gestarla y promoverla -artistas, académicos, periodistas: en suma, los intelectuales- o bien están atrapados en el desencanto ante los proyectos ideológicos a los que se aferraron en el pasado o bien son presa de las veleidades y de las modas culturales de última hora (neoconservadoras y postmodernas) que los llevan a ser parte de la vorágine consumista e individualista de nuestro tiempo.

Allen Cordero Ulate, "Clases medias y movimientos sociales en Costa Rica". Revista de Ciencias Sociales, No. 109, 2005.

ERIC, IDESO, IDIES, IUDOP, Maras y pandillas en Centroamérica (Vol. I). Managua, UCA Publicaciones, 2001.

ERIC, IDESO, IDIES, IUDOP, Maras y pandillas en Centroamérica (Vol. II). San Salvador, UCA Editores, 2004.

Luis Armando González, "Violencia, integración regional y globalización". ECA, No. 595-596, mayojunio de 1998, pp. 433-447.

Luis Armando González, "El movimiento social salvadoreño ante el CAFTA". Texto de la videoconferencia ofrecida por el autor a estudiantes del Postgrado Centroamericano 
en Ciencia Política de la Universidad de Costa Rica (UCR), en el marco del Módulo: "Democracia y resistencia social ante el debilitamiento del Estado-Nación", desarroIlado en la sede de la UCR, del 20 al 24 de octubre de 2008.

Luis Armando González, "Medios de comunicación y construcción social de la violencia". ECA, No. 667, mayo de 2004, pp. 391-405.

Antonio Luis Hidalgo Capitán, "La forzada apertura comercial y el modelo neoliberal de desarrollo en Costa Rica". Revista de Ciencias Sociales, Números 78-79, diciembre 1997-marzo 1998, pp. 51-60.

IUDOP, Victimización y percepción de inseguridad en El Salvador. Con-

\section{NOTAS}

* Licenciado en Filosofía por la Universidad Centroamericana "José Simeón Cañas” y Maestro en Ciencias Sociales por la Facultad Latinoamericana de Ciencias Sociales (FLACSO), sede académica de México.

1 El primer mandato de Óscar Arias fue de 1986 a 1990

2. Andrés Benavente U., "Estallidos sociales y escenarios de ingobernabilidad: consideraciones sobre el rupturismo social en América Latina”. Ponencia presentada en el Seminario Internacional "Objetivos Estratégicos del Hemisferio para la próxima década”. Marzo 2-4, 2006, p. 2.

3. Diego Achard y Manuel Flores. Gobernabilidad: un reportaje de América Latina. México, FCE-PNUD, 1997, p. 28-29. sulta de opinión pública, julio-agosto 2009. Salvador, IUDOP, 2009.

José Luis Martínez, "De la crisis política a la crisis económica". La Honda. Revista Digital, No. 16.

Armando Ortuño, "Panamá: escenarios sociopolíticos de mediano plazo". En Crisis y cambio en América Latina. Cuadernos de gobernabilidad democrática. México, siglo XXI, 2006.

Edelberto Torres-Rivas, La piel de Centroamérica. San José, Costa Rica, FLACSO, 2007.

Paul Kobrak, En pie de lucha. Organización y represión en la Universidad de San Carlos, Guatemala, 1944-1996. Washington, American Asociation for the Advancement of Science, 1999.

4. Ibíd., p. 4.

5. En el caso del Perú, se tiene que decir que la crisis económica estuvo precedida por una profunda crisis política suscitada por los escándalos de corrupción en los que se vio envuelto el gobierno de Alberto Fujimori. Cfr., José Luis Martínez, "De la crisis política a la crisis económica". La Honda. Revista Digital, No. 16. http://www.laondadigital.com/laonda/laonda/001-100/16/ Peru\%20de\%20la\%20crisis\%20politica\%20a\%20la\%20crisis\%20economica. $\mathrm{htm}$

6. Ibíd., p. 11.

7. "Ante crisis habrá fuertes protestas contra políticas neoliberales: Fabiola Alanís". Cuadratín. Agencia Mexicana de Información y Análisis. Morelia, Michoacán. Martes 13 de octubre de 2009. 
8. La Asamblea de los movimientos sociales se realizó en el marco del IX FSM, en Belém, en la Amazonia.

9. "Declaración de la Asamblea de los movimientos sociales". ALAI, América Latina en Movimiento, 31 de enero de 2009.

10. "Posición de los movimientos sociales centroamericanos ante el fracaso de la VII Ronda de negociación Unión Europea/Centroamérica”. Enlazando Alternativas. Red Birregional EuropaAmérica Latina y el Caribe.

11. Cfr. Freddy Quezada, "Los movimientos sociales en Nicaragua". En http://www.geocities.com/Athens/ Pantheon/4255/movsofq.html; Allen Cordero Ulate, "Clases medias y movimientos sociales en Costa Rica". Revista de Ciencias Sociales, No. 109, 2005.

12. Armando Ortuño, "Panamá: escenarios sociopolíticos de mediano plazo". En Crisis y cambio en América Latina. Cuadernos de gobernabilidad democrática. México, siglo XXI, 2006, p. 303.

13. Al respecto, Cfr., Paul Kobrak, En pie de lucha. Organización y represión en la Universidad de San Carlos, Guatemala, 1944-1996. Washington, American Asociation for the Advancement of Science, 1999; Patrick Ball, Paul Kobrak, Herbert F. Spirer, Violencia institucional en Guatemala, 1960-1998. Una reflexión Cuantitativa. Washington, American Asociation for the Advancement of Science, 1999; Luis Armando González, "1970-1992: dos décadas de violencia socio política en El Salvador". ECA, No. 588, octubre de 1992.

14. Luis Armando González, "El movimiento social salvadoreño ante el CAFTA".
Texto de la videoconferencia ofrecida por el autor a estudiantes del Postgrado Centroamericano en Ciencia Política de la Universidad de Costa Rica (UCR), en el marco del Módulo: "Democracia y resistencia social ante el debilitamiento del Estado-Nación”, desarrollado en la sede de la UCR, del 20 al 24 de octubre de 2008.

15. Cfr. Óscar René Vargas, “El fracaso neoliberal en Nicaragua”. En http://www.rlp.com.ni/noticias $/ 2835$

16. "Daniel Ortega presidente: del poder 'desde abajo' al gobierno. Envío, No. 296, noviembre de 2006. http://www.envio.org.ni/ articulo/3418

17. "Elecciones municipales: una crisis anunciada- Perdió Nicaragua”. Envío, No.320, noviembre de 2008. http://www.envio.org.ni/articulo/3890

18. Brayan Brenes, "Centroamérica frente a una crisis histórica". Estrategia Internacional, No. 25, diciembre 2008-enero 2009, p. 284.

19. En líderes políticos. Biografías. http:// www.cidob.org/es/documentacion/ biografias_lideres_politicos/america_central_y_caribe/costa_rica/Óscar_arias_sanchez

20. Ibíd.

21. Lo cual no quiere decir, sin embargo, que en este país no se haya implementado un programa neoliberal en los años ochenta y noventa. Cfr., Antonio Luis Hidalgo Capitán, "La forzada apertura comercial y el modelo neoliberal de desarrollo en Costa Rica”. Revista de Ciencias Sociales, Números 78-79, diciembre 1997-marzo 1998, pp. 5160 . 
22. Por ejemplo, el Arzobispo de San José, Hugo Barrantes, sostuvo, en vísperas de las elecciones que dieron el triunfo Óscar Arias, que el neoliberalismo tenía secuestrado al país, pues un grupo muy pequeño de ricos empresarios y políticos tiene "secuestrada" la democracia costarricense, mientras que "la clase media está al borde de la pobreza y los pobres al punto de la miseria". Radio La Primerísima, 21 de enero de 2006. http://www.radiolaprimerisima.com/ noticias/1119

23. Edelberto Torres-Rivas, La piel de Centroamérica. San José, Costa Rica, FLACSO, 2007, p. 187.

24. Ibíd.

25. Armando Ortuño, Ibíd., p. 307.

26. "Panamá: gobierno de Martín Torrijos cuenta con $67.2 \%$ de aprobación". La Gente, Managua, 9 de septiembre de 2006. http://www.radiolaprimerisima. com/noticias/3414

27. Guillermo Endara y Mireya Moscoso salieron de las filas del Partido Arnulfista, mientras que Ernesto Pérez Balladares y Martín Torrijos salieron de las filas del PRD.

28. Tribuna Iberoamericana: Álvaro Colom, Presidente Electo de la República de Guatemala en Casa de América. http:// www.casamerica.es/prensa/sala-deprensa/tribuna-iberoamericana-alvarocolom-presidente-electo-de-la-republica-de-guatemala-en-casa-de-america

29. En respaldo de Colom, unas $40 \mathrm{mil}$ personas, llegadas de los lugares más apartados del país colmaron, siempre en mayo, la Plaza de la Constitución, frente al Palacio Nacional de la Cultura, para apoyar a quien consideran "el presidente de los pobres". Los opositores a Colom, vestidos de blanco, salieron también a las calles, para manifestarle su rechazo. "Guatemala se divide por acusación de asesinato contra Álvaro Colom". Guatemala, EFE, 17 de mayo de 2009.

30. La principal prueba en contra de Álvaro Colom fue un video en el que Rosenberg acusa al presidente, a su esposa y a altos funcionarios del gobierno de ordenar su ejecución. Asimismo, Rosenberg asegura que el motivo de su muerte estaría relacionado con el asesinato del que fue su cliente, el industrial Khalil Musa, quien fue abatido junto a su hija el pasado 14 de marzo de 2009. El gobierno rechazó las acusaciones y pidió a la Comisión Internacional Contra la Impunidad en Guatemala (CICIG) que investigue el crimen. El portavoz presidencial, Fernando Barillas, dijo que las acusaciones buscaban crear una "crisis política” en el país.

31. "Álvaro Colom acusa a opositores de desestabilización”.

Ciudad Guatemala. La Voz.com. , 15 mayo del 2009

32. "Hambruna en Guatemala". La Jornada, 27 de agosto de 2009; "Gobierno declara alerta por hambruna en Guatemala". El Mundo, 10 de septiembre de 2009.

33. Incluso lo que pudo haber sido un desborde popular - la marcha campesina del 12 de octubre de 2009- no revistió tal carácter, pese a que los manifestantes reclamaron al gobierno el incumplimiento de importantes acuerdos con el sector campesino. "Guatemala: gigantesco caos vehicular como medio de protesta campesina". Tulum, 12 de octubre de 2009. http://revistatulum. wordpress.com

34. Manuel Díaz Galeas, "Honduras 2005: primer vistazo a unas elecciones generales controversiales", 6 


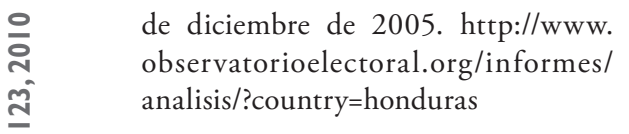

35. No entramos aquí la disputa acerca de si se trató o no de un Golpe de Estado —o si el mismo estuvo justificado o no-, sino que nos atenemos —al aceptarlo como un golpe de Estadoa la postura asumida por la comunidad internacional al respecto.

36. "Manuel Zelaya, en un sainete bananero". ABC.ES, lunes 19 de octubre de 2009.

37. Cfr., Luis Armando González, “Balance preliminar de la coyuntura política 2009”. En www.sanchezceren.com/index.php?...la...2009..

38. Al respecto, la evaluación de los primeros 100 días de Mauricio Funes, realizada por el Instituto Universitario de Opinión Pública (IUDOP), de la UCA, arrojó que $68.4 \%$ de la población encuestada opinaba que Funes estaba gobernando bien (contra un $11.3 \%$ que dijo que lo estaba haciendo mal), mientras que $59.1 \%$ sostenía que su imagen había mejorado desde que asumió la presidencia (contra un 11.2\% que dijo que había empeorado). Y en el tema concreto de la crisis económica, el $71.5 \%$ de la población encuestada afirmó que la medidas del plan anticrisis propuesto por el gobierno reducirían en algo o en mucho su impacto. Cfr., IUDOP, "Los salvadoreños y salvadoreñas evalúan los primeros cien días de Mauricio Funes", Boletín de Prensa, 7 de septiembre de 2009.

39. Sergio Arauz, "Entrevista con Medardo González, coordinador general del FMLN". El Faro. Net, 22 de octubre de 2009.

40. Es probable que el "desgaste" en la alianza que llevó a Funes a la presiden- cia no le esté permitiendo capitalizar la crisis institucional que se ha desatado en ARENA, a partir de la rebelión de 12 de sus diputados, y que podría —si se profundiza - cambiar la correlación de fuerzas existente en la Asamblea Legislativa a favor de las iniciativas de izquierda. De hecho, uno de los mayores temores en los círculos de la derecha salvadoreña es las ventajas políticas que podría dar al FMLN, a nivel legislativo, de la ruptura interna en el partido. "Rebelión de diputados agrava crisis de oposición salvadoreña”. Notimex, 23 de octubre de 2009. http://sdpnoticias.com/sdp/contenido/2009/10/23/4/518347\#

41. Esa pobreza estructural forzó un movimiento migratorio de amplias proporciones (en Guatemala, Honduras, El Salvador y Nicaragua) que se tradujo en un importante flujo de remesas que contribuyó a paliar la situación de pobreza. En el marco de la crisis, las remesas disminuyeron, con la cual la precariedad se hizo presente, de nuevo, en aquellos hogares que dependían de las remesas recibidas.

42. ERIC, IDESO, IDIES, IUDOP, Maras y pandillas en Centroamérica (Vol. I). Managua, UCA Publicaciones, 2001; Maras y pandillas en Centroamérica (Vol. II). San Salvador, UCA Editores, 2004.

43. Cfr., Luis Armando González, "Violencia, integración regional y globalización". ECA, No. 595-596, mayo-junio de 1998, pp. 433-447.

44. Al grado de que, según el PNUD, en el caso de El Salvador (que está seguido de cerca por Honduras y Guatemala), se trata de una epidemia. El PNUD estima que en Centroamérica han sido asesinadas unas 79 mil personas en los últimos 6 años. Cfr., Informe de desarro- 
Ilo humano para América Central, 20092010. San Salvador, PNUD, 2009.

45. Cfr., Luis Armando González, "Medios de comunicación y construcción social de la violencia”. ECA, No. 667, mayo de 2004, pp. 391-405.
46. Cfr., Luis Armando González, "Miedo social a flor de piel”. El Independiente, jueves 22 de octubre de 2009, p. 3.

47. IUDOP, Victimización y percepción de inseguridad en El Salvador. Consulta de opinión pública, julio-agosto 2009. Salvador, IUDOP, 2009.

48. Ibíd., pp. 21-24. 